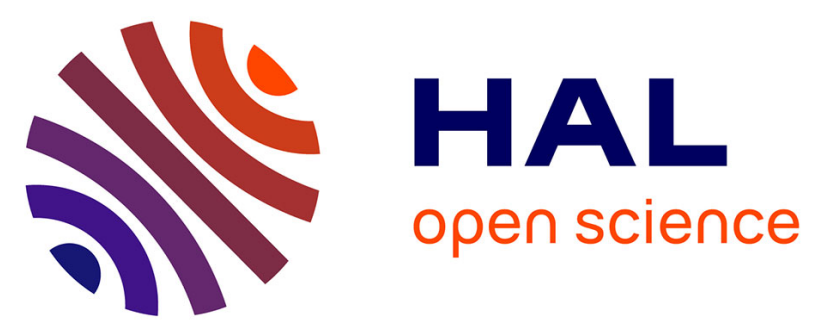

\title{
Modeling and Inversion in Thermal Infrared Remote Sensing over Vegetated Land Surfaces
}

\author{
Frédéric Jacob, T. Schmugge, Albert Olioso, A. French, Dominique Courault, \\ K. Ogawa, F. Petitcolin, Ghani Chehbouni, A. Pinheiro, J. Privette
}

\section{To cite this version:}

Frédéric Jacob, T. Schmugge, Albert Olioso, A. French, Dominique Courault, et al.. Modeling and Inversion in Thermal Infrared Remote Sensing over Vegetated Land Surfaces. S. Liang. Advances in Land remote Sensing: System, Modeling, Inversion and Application, 354, Springer, pp.245-292, 2008, Advances in land remote sensign: system, modeling, inversion and application, 978-1-4020-6449-4 ; 978-94-007-9868-7 ; 978-1-4020-6450-0. 10.1007/978-1-4020-6450-0_10 . ird-00392669

\section{HAL Id: ird-00392669 https://hal.ird.fr/ird-00392669}

Submitted on 9 Jun 2009

HAL is a multi-disciplinary open access archive for the deposit and dissemination of scientific research documents, whether they are published or not. The documents may come from teaching and research institutions in France or abroad, or from public or private research centers.
L'archive ouverte pluridisciplinaire HAL, est destinée au dépôt et à la diffusion de documents scientifiques de niveau recherche, publiés ou non, émanant des établissements d'enseignement et de recherche français ou étrangers, des laboratoires publics ou privés. 


\section{Chapter 10}

\section{Modeling and Inversion in Thermal Infrared Remote Sensing over Vegetated Land Surfaces}

Frédéric Jacob, Thomas Schmugge, Albert Olioso, Andrew French, Dominique Courault, Kenta Ogawa, Francois Petitcolin, Ghani Chehbouni, Ana Pinheiro, and Jeffrey Privette

Frédéric Jacob

Formerly at Remote Sensing and Land Management Laboratory

Purpan Graduate School of Agriculture, Toulouse, France

Institute of Research for the Development

Laboratory for studies on Interactions between Soils - Agrosystems - Hydrosystems

UMR LISAH SupAgro/INRA/IRD, Montpellier, France

e-mail: frederic.jacob@supagro.inra.fr

Thomas Schmugge

Gerald Thomas Professor of Water Resources

College of Agriculture

New Mexico State University, Las Cruces, NM, USA

Albert Olioso and Dominique Courault

National Institute for Agronomical Research

Climate - Soil - Environment Unit

UMR CSE INRA/UAPV, Avignon, France

Andrew French

United States Department of Agriculture/Agricultural Research Service

US Arid Land Agricultural Research Center, Maricopa, AZ, USA

Kenta Ogawa

Department of Geo-system Engineering, University of Tokyo

and Hitachi Ltd, Tokyo, Japan

Francois Petitcolin

ACRI-ST, Sophia Antipolis, France

Ghani Chehbouni

Institute of Research for the Development

Center for Spatial Studies of the Biosphere

UMR CESBio CNES/CNRS/UPS/IRD, Toulouse, France

Ana Pinheiro

Biospheric Sciences Branch, NASA's GSFC, Greenbelt, MD, USA

Jeffrey Privette

NOAA's National Climatic Data Center, Asheville, NC, USA 


\begin{abstract}
Thermal Infra Red (TIR) Remote sensing allow spatializing various land surface temperatures: ensemble brightness, radiometric and aerodynamic temperatures, soil and vegetation temperatures optionally sunlit and shaded, and canopy temperature profile. These are of interest for monitoring vegetated land surface processes: heat and mass exchanges, soil respiration and vegetation physiological activity. TIR remote sensors collect information according to spectral, directional, temporal and spatial dimensions. Inferring temperatures from measurements relies on developing and inverting modeling tools. Simple radiative transfer equations directly link measurements and variables of interest, and can be analytically inverted. Simulation models allow linking radiative regime to measurements. They require indirect inversions by minimizing differences between simulations and observations, or by calibrating simple equations and inductive learning methods. In both cases, inversion consists of solving an ill posed problem, with several parameters to be constrained from few information.

Brightness and radiometric temperatures have been inferred by inverting simulation models and simple radiative transfer equations, designed for atmosphere and land surfaces. Obtained accuracies suggest refining the use of spectral and temporal information, rather than innovative approaches. Forthcoming challenge is recovering more elaborated temperatures. Soil and vegetation components can replace aerodynamic temperature, which retrieval seems almost impossible. They can be inferred using multiangular measurements, via simple radiative transfer equations previously parameterized from simulation models. Retrieving sunlit and shaded components or canopy temperature profile requires inverting simulation models. Then, additional difficulties are the influence of thermal regime, and the limitations of spaceborne observations which have to be along track due to the temperature fluctuations. Finally, forefront investigations focus on adequately using TIR information with various spatial resolutions and temporal samplings, to monitor the considered processes with adequate spatial and temporal scales.
\end{abstract}

\title{
10.1 Introduction
}

Using TIR remote sensing for environmental issues have been investigated the last three decades. This is motivated by the potential of the spatialized information for documenting the considered processes within and between the Earth system components: cryosphere [1-2], atmosphere [3-6], oceans [7-9], and land surfaces [10]. For the latter, TIR remote sensing is used to monitor forested areas [11-14], urban areas [15-17], and vegetated areas. We focus here on vegetated areas, natural and cultivated. The monitored processes are related to climatology, meteorology, hydrology and agronomy: (1) radiation, heat and water transfers at the soil-vegetation-atmosphere interface [18-24]; (2) interactions between land surface and atmospheric boundary layer [25]; (3) vegetation physiological processes such as transpiration and water consumption, photosynthetic activity and $\mathrm{CO}_{2}$ uptake, vegetation growth and biomass production [26-39]; (4) soil processes such as respiration 
and $\mathrm{CO}_{2}$ uptake, evapotranspiration and water depletion, spatio-temporal variability of soil moisture [39, 40-43]; (5) long-term dynamics of land cover [44], land surface radiative budget [45-48], water shortage and drought [49].

TIR remote sensing allow retrieving emissivity and temperature, with various complexity degrees presented in Section 10.2. The remotely sensed information is collected from operational and prospective sensors, listed in Section 10.3. This information is characterized by temporal and spatial dimensions (Section 10.3.1), as well as by spectral and directional dimensions (Section 10.3.2). Then, inferring emissivity and temperature consists of developing and inverting modeling tools, by exploiting the dimensions of the collected information (Section 10.4). Based on TIR fundamentals (Section 10.4.1), simple radiative transfer equations directly link measurements to emissivities and temperatures of interest (Section 10.4.2), and simulation models describe the influence of radiative regime on measurements (Section 10.4.3). However, simple radiative transfer equations must be parameterized, and simulation models require significant information. Further, inversion is not trivial: most of simulation models are not directly invertible, and the numerous parameters to be constrained from remote sensing make inversion is often an ill posed problem (Section 10.4.4). The several solutions proposed to overcome these difficulties are assessed using validations, intercomparisons, and sensitivity studies (Section 10.5).

Current limitations and proposed solutions are presented with an increasing complexity for the temperatures of interest (Section 10.6). Atmospheric perturbations are corrected by inverting modeling tools for atmosphere, and surface brightness temperature measurements are simulated using modeling tools for land surfaces (Section 10.6.1). Surface emissivity effects are removed using simple radiative transfer equations (Section 10.6.2). Reported performances suggest accuracies rather close to requirements, though refinements are necessary. Recovering temperature for the one source modeling of heat transfers is still not trivial, since the required parameterization significantly varies in time and space (Section 10.6.3). Recent studies suggested focusing on more elaborated temperatures: soil and vegetation components, optionally sunlit and shaded, and canopy temperature profile. Their retrieval is forthcoming challenge, with efforts on measuring, modeling and inversion (Section 10.6.4). The paper ends with forefront investigations about space and time issues in TIR remote sensing: monitoring land processes with adequate spatial scales and temporal samplings, by using available remote sensing observations (Section 10.7).

\subsection{Land Surface Emissivity/Temperature from TIR Remote Sensing}

This section defines the various terms considered in TIR remote sensing, which are related to land surface emissivity and temperature. We focus on their physical definitions and various interests. The corresponding equations are detailed in Section 10.4 . 
- Surface brightness temperature is equivalent to the radiance outgoing from the target, by assuming a unity emissivity [50], and corresponds to the basic TIR remote sensing measurement. It is recovered from at sensor measurements performing atmospheric corrections. It can be assimilated, using modeling tools for land surface, into process models such as SVAT and crop models [18, 38, 39, 43].

- Ensemble waveband emissivity is needed to derive radiometric temperature from brightness temperature $[50,51]$. It is also useful for retrieving ensemble broadband emissivity, a key parameter for land surface radiative budget [52-54].

- Ensemble radiometric temperature is emissivity normalized [50, 51]; and corresponds to kinetic temperature for an homogeneous and isothermal surface [55]. It is used to estimate surface energy fluxes and water status from spatial variability indicators: the vegetation index / temperature triangle [41, 56-58]; or the albedo / temperature diagram $[23,37,59,60]$. It is also used for retrieving soil and vegetation temperatures from two source energy balance modeling [19, 24].

- Aerodynamic temperature is air temperature at the thermal roughness length [50]. It is the physical temperature to be used with one source models of surface energy fluxes based on excess resistance [61-63]. These can be SVAT models [39, 64]; or energy balance models [22, 23, 37, 59, 60, 65, 66].

- Soil and vegetation temperatures correspond to kinetic [67] or radiometric [68] temperatures. They are often used for two-source modeling. The latter can be SVAT models [43, 67, 69]; or energy balance models [70, 20, 71]. Retrieving these temperatures requires an adequate estimation of directional ensemble emissivity.

- Sunlit and shaded components are refinements of soil and vegetation temperatures. They can significantly differ, according to various factors which drive the thermal regime: the water status, the solar exposure resulting from the canopy geometry and the illumination direction. These components are of interest for understanding canopy directional brightness and radiometric temperatures [58, 72-74].

- Canopy temperature profile, from the soil surface to the top of canopy, is the finest temperature one can consider. Similarly to sunlit and shaded components for soil and vegetation temperatures, this thermal regime is considered for understanding canopy directional brightness and radiometric temperatures, in relation with local energy balance within the canopy [75-78].

The seek accuracies vary from one application to another,according to the sensitivities of process models. For temperature, the goal is accuracy better than $1 \mathrm{~K}$ [79]. For emissivity, the goal is absolute accuracy better than 0.01 [80]. Recovering both relies on exploiting the dimensions of the TIR remotely sensed information.

\subsection{Available Information from TIR Remote Sensing}

The four dimensions of the remotely sensed information are temporal and spatial (Section 10.3.1), and spectral and directional (Section 10.3.2). Due to orbital rules 
and technological limitations, current spaceborne sensors cannot provide full information over these dimensions. Further, the latter can be linked, according to the mission objectives: a daily monitoring with sunsynchronous sensor requires a kilometric resolution with an across track angular sampling. Exploratory missions with airborne and ground based sensors are under progress, for assessing the potential of original remotely sensed information. Table 10.1 provides an overview of the main operational and prospective sensors. We deal here with recent, current and forthcoming US and EU missions.

\subsubsection{Temporal and Spatial Capabilities}

The temporal dimension corresponds to the time interval between consecutive observations. It is of importance for monitoring land surface temperature and related processes: radiative and convective transfers, soil respiration and vegetation physiological activity. The spatial dimension corresponds to the ground resolution of the measurements. It is of importance for the meaning of surface temperature collected over kilometric size pixels which include different land units. Both dimensions are strongly correlated for current TIR spaceborne sensors: high temporal samplings for finer monitoring correspond to coarse spatial resolutions with larger heterogeneity effects, and reversely.

The highest temporal samplings are provided by geostationary sensors: 15-30 min with GOES Imager [81] and MSG/SEVIRI [82], corresponding to ground resolutions between 2 and $4 \mathrm{~km}$. Intermediate scales correspond to kilometric resolution sensors onboard sunsynchronous platforms, providing daily nighttime and daytime observations: NOAA/AVHRR [83], ADEOS/GLI [84], and Terra-Aqua/MODIS [85]. A 3 day temporal sampling with a $1 \mathrm{~km}$ resolution has been provided by ERS/ATSR-1 and -2, and ENVISAT/AATSR [86]. The highest spatial resolutions are 60 and $120 \mathrm{~m}$ from Landsat/TM \& ETM [87], and $90 \mathrm{~m}$ from Terra/ASTER [88]; with 16-day temporal samplings. ASTER and Landsat/ETM missions have limited lifetimes, with currently no follow on TIR high spatial resolution missions from space.

Regarding current possibilities, new spaceborne sensors are demanded, to monitor land processes with adequate temporal and spatial scales. Past missions IRSUTE and SEXTET proposed 40-60 m spatial resolutions with a 1-day revisit $[89,90]$ and SPECTRA proposed $50 \mathrm{~m}$ with 3 days [91]. MTI mission offers a $20 \mathrm{~m}$ resolution with a 7-day revisit [92], but the military context restricts the data access. Airborne prospective observations have allowed studying temporal and spatial issues, with metric resolutions and adjustable revisits. Let us cite the airborne missions TIMS [93], DAIS [94], MAS [95] and MASTER [96]; and the airborne based ReSeDA program [97-99]. 
Table 10.1 Nominal characteristics for operational and prospective sensors; in relation with recent, current and forthcoming US and EU missions. VZA means View Zenith Angle, VAA means View Azimuth Angle. Across (respectively along) track means viewing directions in a plan perpendicular (respectively parallel) to the satellite path.

\begin{tabular}{|c|c|c|c|c|}
\hline Sensor & $\begin{array}{l}\text { Daytime } \\
\text { sampling }\end{array}$ & $\begin{array}{c}\text { Spatial } \\
\text { resolution }\end{array}$ & $\begin{array}{l}\text { Spectral } \\
\text { features }\end{array}$ & $\begin{array}{l}\text { Directional } \\
\text { features }\end{array}$ \\
\hline \multicolumn{5}{|l|}{ Spaceborne } \\
\hline MSG & \multirow{2}{*}{$15 \mathrm{mn}$} & \multirow{2}{*}{$3 \mathrm{~km}$} & $1 \mathrm{MIR}: 3.9 \mu \mathrm{m}$ & \multirow{2}{*}{$\begin{array}{l}1 \text { latitude- } \\
\text { dependent VZA }\end{array}$} \\
\hline SEVIRI & & & 5 TIR: $8.7,9.7,10.8,12,13.4 \mu \mathrm{m}$ & \\
\hline GOES 10 and 12 & \multirow{2}{*}{$30 \mathrm{mn}$} & \multirow{2}{*}{$2-4 \mathrm{~km}$} & $1 \mathrm{MIR}: 3.7 \mu \mathrm{m}$ & \multirow{2}{*}{$\begin{array}{l}1 \text { latitude- } \\
\text { dependent VZA }\end{array}$} \\
\hline Imager & & & 2 TIR: $10.8,12 \mu \mathrm{m}$ & \\
\hline NOAA $15-17$ & \multirow{2}{*}{1 day } & \multirow{2}{*}{$1 \mathrm{~km}$} & $1 \mathrm{MIR}: 3.8 \mu \mathrm{m}$ & \multirow{2}{*}{$\begin{array}{l}\text { Across track } \\
\text { VZA: } \pm 55^{\circ}\end{array}$} \\
\hline AVHRR / 3 & & & 2 TIR: $11,12 \mu \mathrm{m}$ & \\
\hline Terra-Aqua & \multirow{2}{*}{1 day } & \multirow{2}{*}{$1 \mathrm{~km}$} & 3 MIR: $3.8,3.95,4.1 \mu \mathrm{m}$ & Across track \\
\hline MODIS & & & 3 TIR: $8.6,11,12 \mu \mathrm{m}$ & $\mathrm{VZA}: \pm 55^{\circ}$ \\
\hline ADEOS & \multirow{2}{*}{1 Day } & \multirow{2}{*}{$1 \mathrm{~km}$} & $1 \mathrm{MIR}: 3.7 \mu \mathrm{m}$ & Across track \\
\hline GLI & & & 3 TIR: $8.6,10.8,12 \mu \mathrm{m}$ & $\mathrm{VZA}: \pm 40^{\circ}$ \\
\hline ERS-ATSR 1 and 2 & \multirow{2}{*}{3 days } & \multirow{2}{*}{$1-2 \mathrm{~km}$} & $1 \mathrm{MIR}: 3.7 \mu \mathrm{m}$ & Along track \\
\hline ENVISAT-AATSR & & & 2 TIR: $10.8,12 \mu \mathrm{m}$ & VZA: $0,55^{\circ}$ \\
\hline Landsat 5-7 & \multirow{2}{*}{16 days } & \multirow{2}{*}{$120 \mathrm{~m}$} & 1 TIR $11.5 \mathrm{um}$ & \multirow{2}{*}{$\begin{array}{l}\text { Close nadir } \\
\text { VZA }\end{array}$} \\
\hline TM and ETM & & & 1 IIR. $11.3 \mu \mathrm{m}$ & \\
\hline $\begin{array}{l}\text { Terra } \\
\text { ASTER }\end{array}$ & 16 days & $90 \mathrm{~m}$ & 5 TIR: $8.3,8.6,9,10.7,11.3 \mu \mathrm{m}$ & $\begin{array}{l}\text { Close nadir } \\
\text { VZA }\end{array}$ \\
\hline \multicolumn{5}{|l|}{ Airborne } \\
\hline $\begin{array}{l}\text { TIMS } \\
\text { (multispectral) }\end{array}$ & - & $1-5 \mathrm{~m}$ & $\begin{array}{c}6 \text { TIR: } 8.4,8.8,9.2, \ldots \\
\ldots 9.9,10.7,11.7 \mu \mathrm{m}\end{array}$ & $\begin{array}{l}\text { Across track } \\
\text { VZA: } \pm 38^{\circ}\end{array}$ \\
\hline DAIS & \multirow{2}{*}{ - } & \multirow{2}{*}{$1-5 \mathrm{~m}$} & 6 TIR: $8.7,9.7,10.5, \ldots$ & \multirow{2}{*}{$\begin{array}{l}\text { Across track } \\
\text { VZA: } \pm 26^{\circ}\end{array}$} \\
\hline (multispectral) & & & $\ldots 11.4,12.0,12.7 \mu \mathrm{m}$ & \\
\hline MAS / MASTER & \multirow[t]{4}{*}{ - } & \multirow{4}{*}{$1-5 \mathrm{~m}$} & 10 TIR: $7.8,8.2,8.6,9.1,9.7, \ldots$ & Across track \\
\hline (multispectral) & & & $\ldots 10.1,10.6,11.3,12.1,12.9 \mu \mathrm{m}$ & VZA: $\pm 40^{\circ}$ \\
\hline SEBASS & & & MIR: $[2.5-5.3] \mu \mathrm{m}$ & Close nadir \\
\hline (hyperspectral) & & & $\begin{array}{l}\text { TIR: }[7.6-13.5] \mu \mathrm{m} \\
\text { Spectral resolution }>0.1 \mu \mathrm{m}\end{array}$ & VZA \\
\hline Ground based & & & & \\
\hline $\begin{array}{l}\text { Two temperature } \\
\text { Box method }\end{array}$ & & $\sim 50 \mathrm{~cm}$ & 1 broadband over $[8-13] \mu \mathrm{m}$ & Nadir VZA \\
\hline Hyperspectral FTIR & & Few $\mathrm{cm}$ & Optical spectral range: $[2-20] \mu \mathrm{m}$ & Nadir VZA \\
\hline BOMEM suite & & Few cm & Spectral resolution: $1 \mathrm{~cm}^{-1}$ & \\
\hline Goniometric & & Few $\mathrm{cm}$ & 1 hroadhand over [8-13] um & $\mathrm{VZA} \in\left[0-90^{\circ}\right]$ \\
\hline systems & & Few cm & I broadband over $[8-13] \mu \mathrm{m}$ & $\mathrm{VAA} \in\left[0-360^{\circ}\right]$ \\
\hline
\end{tabular}




\subsubsection{Spectral and Directional Capabilities}

The spectral dimension corresponds to the number and location of sensor wavebands within the TIR and optionally the MIR domains. The directional dimension corresponds to the number and angular distribution of viewing directions. Both dimensions are used for recovering emissivities and temperatures via modeling tools.

The basic spectral configuration corresponds to TM and ETM, with 1 channel. Richer information is provided via two channels with GOES Imager, AVHRR and the ATSR suite; three channels with MODIS and GLI; and five channels with SEVIRI and ASTER. Additional MIR information can be combined with TIR information, to be used with continuous observations from geostationary sensors (SEVIRI, GOES Imager), or day night observations from sunsynchronous sensors (AVHRR, MODIS).

The basic directional configuration corresponds to SEVIRI, GOES Imager, TM, ETM, and ASTER; with a single viewing direction. Richer information is collected from across track viewing with AVHRR, MODIS, GLI; and along track viewing with the ATSR suite. Across track viewing allows a daily monitoring, while sampling the angular dynamic within a given temporal window (16 days for MODIS). This is of interest for stable surface properties such as emissivity. For surface temperature which fluctuates, capturing the angular dynamic requires almost simultaneous observations. This is possible with ATSR along track bi-angular observations only, which is limited.

Future spaceborne missions will pursue current ones for long-term records: the GOES suite [100], NPOESS/VIIRS following AVHRR and MODIS [101]. MTI provides original information: $2 \mathrm{MIR} / 3$ TIR bands, $0^{\circ}$ and $50^{\circ}$ along track. At the airborne level, the spectral dimension has been investigated with multispectral (TIMS, DAIS, MAS \& MASTER) and hyperspectral (SEBASS [102]) sensors, and the directional dimension has been assessed with video cameras (see [103] with the ReSeDA program). At the ground level, the spectral dimension has been explored with hyperspectral sensors (FTIR BOMEM [104]), or with broadband radiometers [105-107], and the directional dimension has been examined with goniometric systems $[58,108,109]$.

In the context of monitoring land processes, the various types of information presented here are valuable for recovering land surface emissivity and temperature. Using this information requires designing modeling tools and inversion methods, either under development for prospective studies or with operational capabilities.

\subsection{Developing Modeling Tools and Inversion Methods}

Modeling tools aim at forwardly simulating, with different complexities, measured brightness temperature from emissivities and temperatures of interest. Table 10.2 provides an overview of the modeling tools currently used. Based on TIR fundamentals (Section 10.4.1), simple radiative transfer equations directly link measurements 
Table 10.2 Listing of the modeling tools currently used, with an increasing complexity. The second rightmost column gives the related medium, and the rightmost column gives the types of land surface emissivity and temperature currently investigated with each tool. We deal here with the modeling of atmospheric radiative transfer in the context of performing atmospheric corrections.

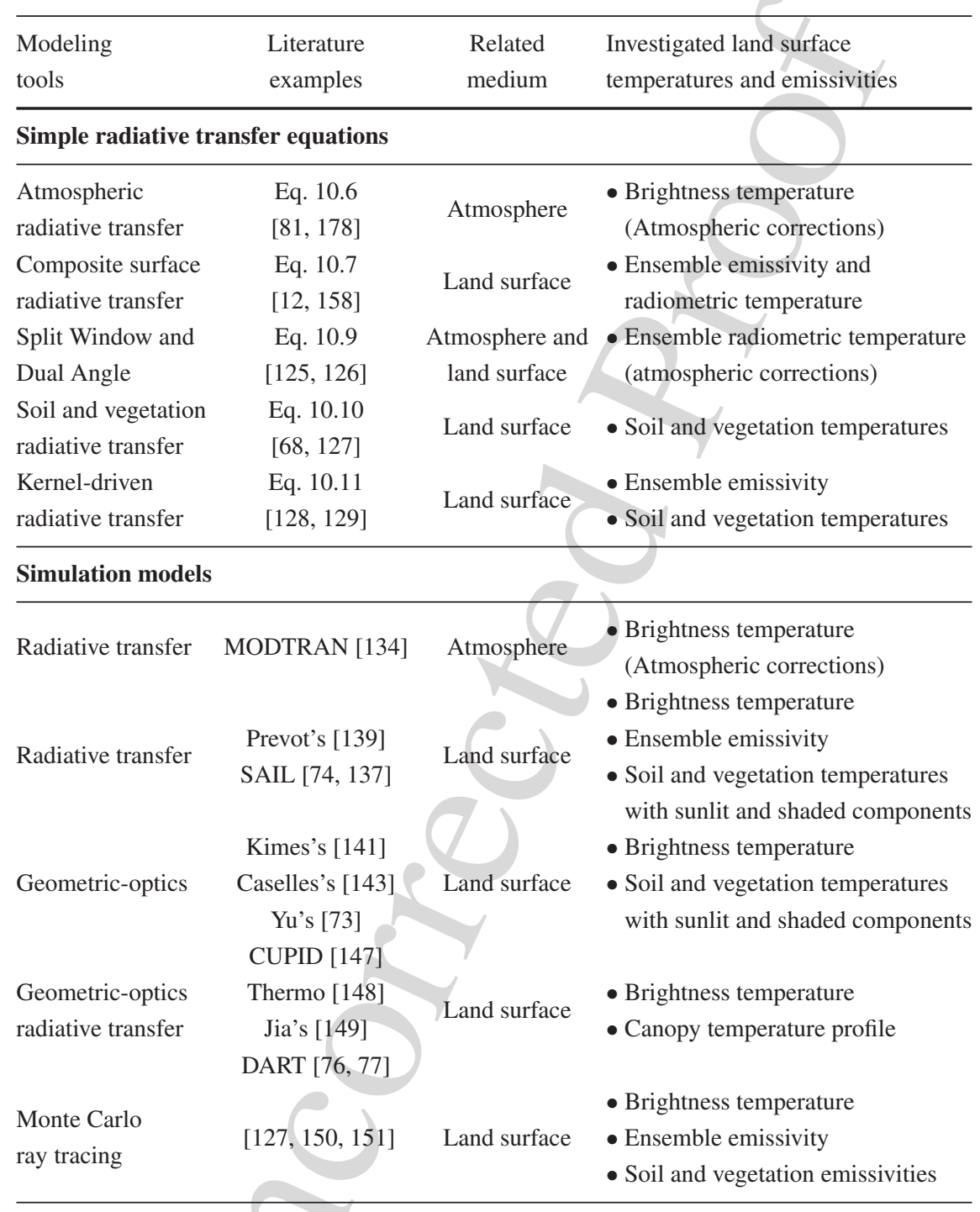

to emissivities and temperatures of interest (Section 10.4.2), and simulation models describe the influence of radiative regime on measurements (Section 10.4.3). Next, inversion methods aim at backwardly retrieving emissivities and temperatures of interest from measurements (Section 10.4.4). 


\subsubsection{Fundamentals in TIR Remote Sensing}

The use of TIR remote sensing to infer the temperatures of interest involves an aerodynamic issue for the related temperature, and a radiative issue for the other temperatures.

\subsubsection{Aerodynamic Issue}

Aerodynamic temperature $T_{\text {aero }}$ is not radiative based and cannot be remotely sensed. It is required for one source modeling of surface energy fluxes, since it corresponds to the value of the logarithmic based air temperature profile $T_{\text {air }}(z)$ at thermal roughness length $z_{o h}$ [110]. For a negligible displacement height, sensible heat flux $H$ is expressed from the air temperature gradient between $z_{o h}$ and reference level $z_{\text {ref }}$ :

$$
H=\frac{T_{a i r}\left(z_{o h}\right)-T_{a i r}\left(z_{r e f}\right)}{r_{a h}\left(z_{o h}, z_{r e f}\right)} \quad \text { with } \quad T_{\text {aero }}=T_{\text {air }}\left(z_{o h}\right)
$$

where $r_{a h}\left(z_{o h}, z_{r e f}\right)$ is aerodynamic resistance for heat between $z_{o h}$ and $z_{\text {ref }}$ [111]. Due to larger resistance for heat transfers, $z_{o h}$ is lower than mechanical roughness length $z_{o m}$ [112]. The link between both is the aerodynamic $k B^{-1}$ parameter [113]:

$$
k B^{-1}=\ln \left(\frac{z_{o m}}{z_{o h}}\right)
$$

The physical meanings of $T_{\text {aero }}$ and $z_{o h}$ are equivocal. $T_{\text {aero }}$ is an effective temperature for heat sources that are soil and vegetation [114]. $z_{o h}$ is an effective level for which $T_{\text {air }}=T_{\text {aero }}$. Their retrieval from remote sensing is not trivial (Section 10.6.3). Nevertheless, $T_{\text {aero }}$ can be unequivocally derived from soil and vegetation temperatures $T_{\text {soil }}$ and $T_{\text {veg }}$, by merging one source and two source modeling [20,115]:

$$
T_{\text {aero }}=\frac{\frac{T_{\text {soil }}}{r_{a, \text { soil }}}+\frac{T_{\text {veg }}}{r_{a, v e g}}+\frac{T_{\text {air }}\left(z_{\text {ref }}\right)}{r_{a h}}}{\frac{1}{r_{a, s o i l}}+\frac{1}{r_{a, v e g}}+\frac{1}{r_{a h}}}
$$

where $r_{a, \text { soil }}$ (respectively $r_{a, v e g}$ ) is aerodynamic resistance from the soil (respectively vegetation) to $z_{o m}$, and $r_{a h}$ is aerodynamic resistance from $z_{o m}$ to $z_{r e f}$ [111].

\subsubsection{Radiative Issue}

Apart from aerodynamic temperature, the land surface temperatures inferred from TIR remote sensing are radiative based. Then, fundamentals deal with the TIR radiative regime within atmosphere and over land surfaces. This includes three mechanisms which drive the wave matter interactions: emission, absorption, and 
scattering. Emitted radiance $L(\lambda, \theta, T)$ from a natural object at a kinetic temperature $T$ is written:

$$
L(\lambda, \theta, T)=\varepsilon(\lambda, \theta) B(\lambda, T)=\varepsilon(\lambda, \theta) \frac{C 1 \lambda^{-5}}{\pi\left[\exp \left(\frac{C 2}{T \lambda}\right)-1\right]}
$$

$\lambda$ is the monochromatic wavelength. $\theta$ is the emission direction. $B(\lambda, T)$ is the blackbody emitted radiance, expressed from Planck's Law. C1 and C2 are first and second radiative constants. Emissivity $\varepsilon(\lambda, \theta)$ is the conversion factor from thermodynamic to radiative energy, lower than 1 for natural objects. This so-called e-emissivity definition is linked to emission mechanisms, since it is the ratio of the actual to the blackbody emitted radiances for the same kinetic temperature. Under local thermodynamic equilibrium, Kirchhoff's Law assumes emissivity and absorptivity are equal. For opaque elements, emissivity is then linked to hemisphericaldirectional reflectance $\rho\left(\lambda_{j}, \theta\right)$ :

$$
\varepsilon\left(\lambda_{j}, \theta\right)=1-\rho\left(\lambda_{j}, \theta\right)
$$

$\rho\left(\lambda_{j}, \theta\right)$ is the average of bidirectional reflectance over illumination angles [116]. This so-called r-emissivity definition is derived from Kirchhoff's Law, and therefore linked to reflection mechanisms. Finally, emitted radiance from a given element can be reflected by other elements, inducing changes in radiation path, called scattering effects.

Within atmosphere, scattering is negligible: the radiative regime is driven by the temperature and density of absorbers and emitters (water vapor, $\mathrm{CO}_{2}, \mathrm{O}_{3}, \ldots$ ). A clear atmosphere behaves as an horizontally homogeneous medium: the radiative regime primarily depends on vertical profiles for temperature and density of absorbers and emitters (Fig. 10.1). Over heterogeneous land surfaces with structured patterns, the radiative regime is more complex than within atmosphere: soil and vegetation act as emitters, absorbers and scatterers for canopy and atmospheric irradiances. Additional effects are surface and volume scatterings (Fig. 10.2). Surface scattering corresponds to shadowing effects for a geometric medium, with sunlit and shaded areas. Volume scattering/corresponds to reflections between soil and vegetation: radiation is trapped within the canopy.

TIR remotely sensed measurements result from the processes discussed above. Sensor brightness temperature is driven by vertical profiles for temperatures and densities of atmospheric constituents. Surface brightness temperature results from the radiative regime over a heterogeneous and non isothermal area. Then, emissivity and kinetic temperature are equivocal: the canopy acts as an effective medium with ensemble emissivity and radiometric temperature [50]. Besides, e- and r-emissivities differ according to vegetation amount, since spatial averaging for e-emissivity includes emitted radiance as an additional weighting factor [50, 117]. Due to its simpler formulation, r-emissivity is preferred $[68,71,74,118-120]$. Further, the measured brightness temperature results from emission, but also from absorption and scattering of canopy and atmospheric irradiances. This induces spectral and directional variations, driven by (1) radiative properties of soil and vegetation 


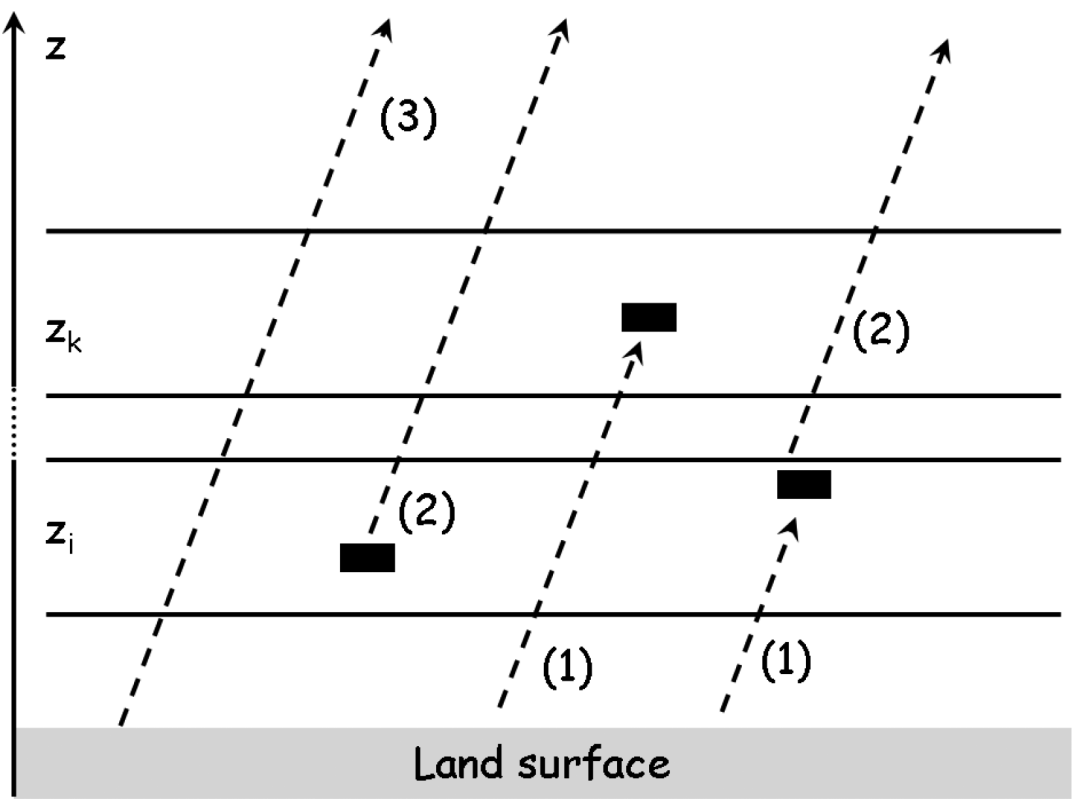

Fig. 10.1 Atmospheric TIR radiative regime for an off nadir propagation. The key processes to be considered for atmospheric corrections are emission and absorption by atmospheric constituents. Within a horizontally homogeneous atmosphere, the radiative regime depends on the vertical fields of temperature and density for emitters and absorbers. Regardless of considered layer $\left(\mathrm{z}_{i}\right.$ or $\left.\mathrm{z}_{k}\right)$, radiative regime is driven by atmospheric absorption (1), atmospheric emission (2), and surface emission through atmosphere transmivity (3). (Adapted from [264].)

(reflectance and emissivity), (2) surface scattering with sunlit and shaded areas, and (3) volume scattering with the cavity effect. These three factors induce ensemble emissivity is anisotropic, with values greater than that of vegetation as the latter quantitatively increases [118, 121, 122].

Various modeling tools have been/developed to simulate sensor and surface brightness temperature measurements. The first way is using simple radiative transfer equations for directly linking measurements to emissivities and temperatures of interest. The second way is using simulation models for understanding the influence of the TIR radiative regime on the measured brightness temperature.

\subsubsection{Simple Radiative Transfer Equations}

Simple radiative transfer equations directly link TIR measurements to emissivities and temperatures of interest. Their advantages are linearity and simplicity, but most of them are limited to homogeneous media by assuming turbidity and azimuthal isotropy. 


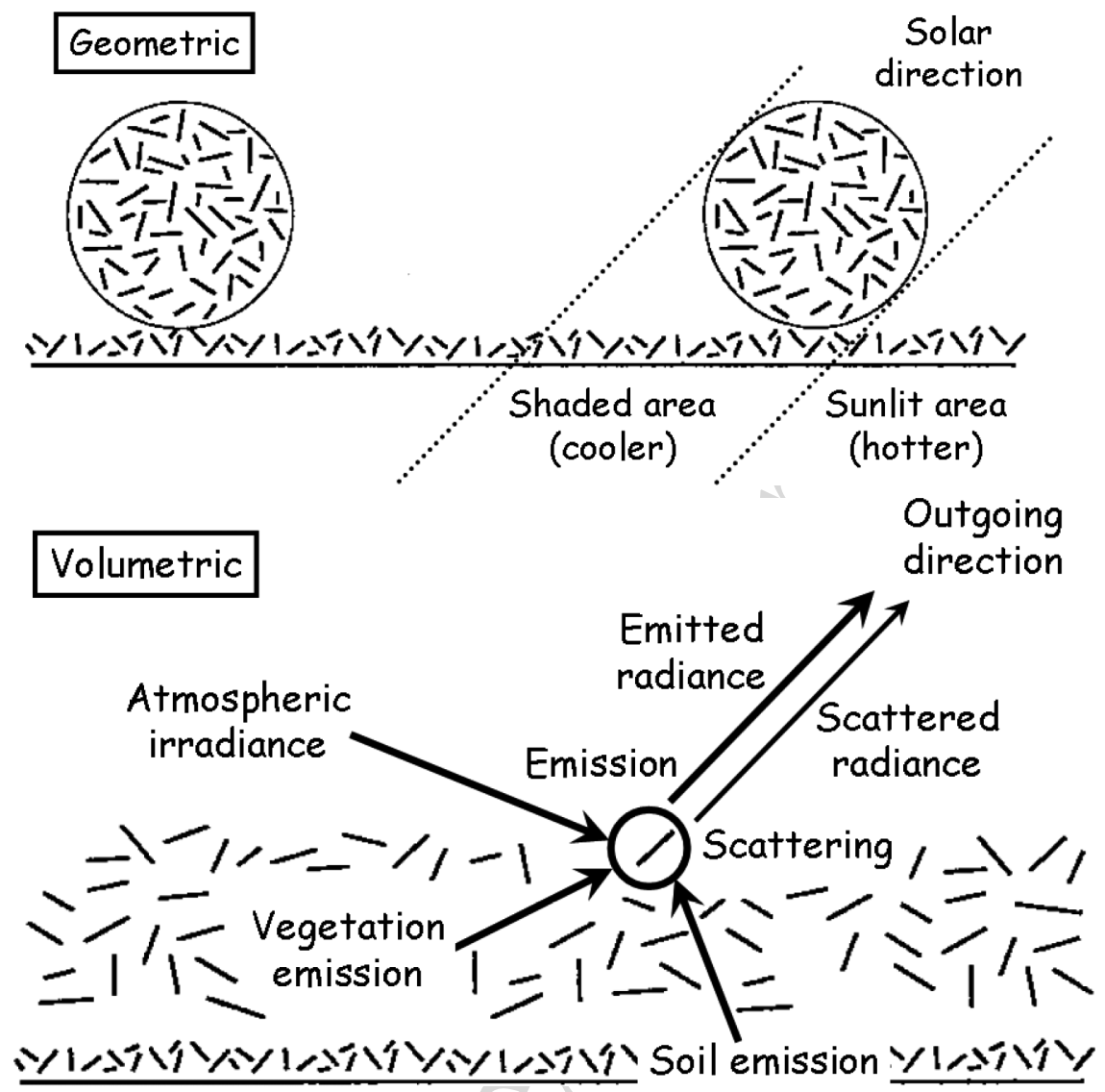

Fig. 10.2 Surface (or geometric) and volume (or volumetric) scattering. Surface scattering induces shadowing effects with hotter and cooler elements. Volume scattering induces an increase of brightness temperature by adding a component to emission. (Adapted from [129].)

Measured brightness temperature at the sensor level $T_{b}^{r s}$ is linked to surface brightness temperature $T_{b}^{s}$ via the atmospheric radiative transfer equation:

$$
B\left(\lambda_{j}, T_{b}^{r s}\left(\theta, \lambda_{j}\right)\right)=B\left(\lambda_{j}, T_{b}^{s}\left(\theta, \lambda_{j}\right)\right) \tau_{a}\left(\theta, \lambda_{j}\right)+B\left(\lambda_{j}, T_{b}^{a \uparrow}\left(\theta, \lambda_{j}\right)\right)
$$

$\theta$ is the view zenith angle. $\lambda_{j}$ is the equivalent waveband over the sensor channel $j$ [123]. $B(\lambda, T)$ is the blackbody emitted radiance, expressed from Planck's Law (Eq. 10.4). $\tau_{a}$ is the atmospheric transmittance, vertically integrated between the surface and the sensor. $B\left(\lambda_{j}, T_{b}^{a \uparrow}\right)$ is the atmospheric upward radiance towards the sensor.

Surface brightness temperature is expressed as the sum of canopy emission and scattering of atmospheric irradiance, via the composite surface radiative transfer equation: 


$$
B\left(\lambda_{j}, T_{b}^{s}\left(\theta, \lambda_{j}\right)\right)=\varepsilon\left(\lambda_{j}, \theta\right) B\left(\lambda_{j}, T_{\text {rad }}(\theta)\right)+\left(1-\varepsilon\left(\lambda_{j}, \theta\right)\right) B\left(\lambda_{j}, T_{b}^{a \downarrow}\left(\lambda_{j}\right)\right)
$$

$B\left(\lambda_{j}, T_{b}^{a \downarrow}\right)$ is the hemispherical average of atmospheric downward radiance. $\varepsilon\left(\lambda_{j}, \theta\right)$ and $T_{\text {rad }}(\theta)$ are ensemble emissivity and radiometric temperature. Ensemble emissivity can be expressed from emissivities of soil $\varepsilon_{\text {soil }}\left(\lambda_{j}\right)$ and vegetation $\varepsilon_{v e g}\left(\lambda_{j}\right)$, with the optional inclusion of a correction term $d \varepsilon$ for the cavity effect [124]:

$$
\varepsilon\left(\lambda_{j}, \theta\right)=F_{\text {soil }}(\theta) \varepsilon_{\text {soil }}\left(\lambda_{j}\right)+F_{\text {veg }}(\theta) \varepsilon_{\text {veg }}\left(\lambda_{j}\right)+4 d \varepsilon F_{\text {veg }}(\theta) F_{\text {soil }}(\theta)
$$

$F_{\text {soil }}(\theta), F_{\text {veg }}(\theta)$ are directional gap and cover fractions, with $F_{\text {soil }}(\theta)=1-F_{\text {veg }}(\theta)$.

Brightness temperature measured from space can be linked to emissivity and radiometric temperature by merging Eqs. 10.6 and 10.7. Another possibility is simultaneously considering atmospheric and surface effects: Split Window (SW) and Dual Angle (DA) methods directly express radiometric temperature $T_{\text {rad }}$ as a spectral or angular difference between two brightness temperatures $T_{b}^{r s}$ at the sensor level $[125,126]$ :

$$
T_{\text {rad }}=T_{b 1}^{r s}+A\left(T_{b 1}^{r s}-T_{b 2}^{r s}\right)+B\left(T_{b 1}^{r s}-T_{b 2}^{r s}\right)^{2}+C \frac{\varepsilon_{1}+\varepsilon_{2}}{2}+D\left(\varepsilon_{1}-\varepsilon_{2}\right)+E
$$

$\varepsilon$ is surface emissivity. A, B, C, D, E are empirical coefficients. Indices 1 and 2 are two spectral channels for SW method, or two view zenith angles for DA method. The angular differencing uses variations in atmospheric transmittance between different paths for two view zenith angles. The spectral differencing uses variations in atmospheric transmittance due to different water vapor absorptions for two spectrally close channels.

The emission term of Eq. 10.7 can be split into soil and vegetation components, which yields the soil and vegetation radiative transfer equation $[68,119,127]$ :

$$
\begin{aligned}
\varepsilon\left(\lambda_{j}, \theta\right) B\left(\lambda_{j}, T_{\text {rad }}(\theta)\right)= & \tau^{\text {can }}(\theta) \varepsilon_{\text {soil }}\left(\lambda_{j}\right) B\left(\lambda_{j}, T_{\text {soil }}\right) \\
& +\omega\left(\theta, \varepsilon_{\text {veg }}\left(\lambda_{j}\right)\right) B\left(\lambda_{j}, T_{\text {veg }}\right)
\end{aligned}
$$

$T_{\text {soil }}$ and $T_{\text {veg }}$ are soil and vegetation radiometric temperatures [68]. $\tau^{\text {can }}(\theta)$ and $\omega\left(\theta, \varepsilon_{\text {veg }}\left(\lambda_{j}\right)\right)$ are vegetation directional transmittance and fraction of emitted radiation. The angular effects can also be described with linear kernel driven approaches, by expressing the directional emission as a linear combination of generic shapes [128]:

$$
\begin{aligned}
& \varepsilon\left(\lambda_{j}, \theta\right) B\left(\lambda_{j}, T_{\text {rad }}(\theta)\right)= \\
& \sum_{i=1}^{N} \beta_{i}\left(\lambda_{j}\right) K_{i}\left(T_{\text {veg }}, T_{\text {soil }}, \varepsilon_{\text {veg }}\left(\lambda_{j}\right), \varepsilon_{\text {soil }}\left(\lambda_{j}\right), \theta, \theta_{s}, \varphi-\varphi_{s}\right)
\end{aligned}
$$

$\theta_{s}$ is the solar zenith angle. $\varphi-\varphi_{s}$ is the relative azimuth between illumination and viewing directions. $\beta_{i, \lambda_{j}}$ are weighting coefficients. Kernels $K_{i}$ describe gray body isotropy, volume scattering, and surface scattering. Various kernel formulations may be proposed, by linearizing different sets of complex equations. Kernel driven approaches are also used to derive ensemble r-emissivity from accurate 
hemispherical - directional reflectance (Eq. 10.5): [129] expressed TIR BRDF as a linear combination of generic shapes, following previous works over the solar domain [130-132].

\subsubsection{Simulation Models}

Simulation models mimic the TIR radiative regime within atmosphere and canopies, to understand spatial, spectral and directional behaviors of brightness temperature measurements. These models are classified here via an increasing complexity: radiative transfer, geometric-optics, geometric-optics/radiative transfer, and ray tracing.

Radiative transfer models are designed for turbid media (atmosphere, homogeneous canopies). Assuming turbidity and azimuthal isotropy, they split the medium into a finite layer number, and account for volume scattering between layers. For the atmosphere, volume scattering is negligible, and each layer is described with temperature and densities of absorbers and emitters. For canopies, soil and vegetation layers are described with temperature; and with densities of absorbers, emitters and scatterers, derived from LAI and LIDF. Brightness temperature is simulated using the stream concept: transmittance, upward and downward radiances are computed for each layer, and vertically integrated (see MODTRAN for atmosphere [133, 134] and SAIL for canopy [68, 74 135-137]. Simulations can also be probabilistic calculations for photon interception, deduced from the directional gap fraction of each layer [118, 138, 139].

Geometric-optics models are designed for structured patterns over land surfaces, such as row crops of cotton or maize. Considering vegetation as an opaque medium, they account for surface scattering with shadowing effects. Sunlit and shaded areas are described via their cross sections, derived from canopy geometry (vegetation height, row size, etc.), illumination and viewing directions, and directional gap fraction within and between rows. Canopy brightness temperature is computed from the resulting spatial distribution of temperature [73, 121,140-143].

The finest radiosity models are geometric-optics/radiative transfer models, designed for complex land surfaces. By accounting for both volume and surface scattering, they are appropriate to vegetation patchworks. They can conjugate a radiative transfer and a geometric-optic module [144, 145]. They can be more complex, such as 3-Dimensional mock-ups based models. This allows a finer description of the radiative regime within canopies, but requires significant information about the micro-scale conditions. Examples are CUPID [146, 147]; Thermo [148, 172]; Jia's model [149], and DART [76, 77]. Further, accounting for convective and energetic transfers allow understanding their influence on the radiative regime, such as with DART-EB [78].

The finest modeling degree is Monte Carlo ray tracing, which stochastically calculates photon trajectories within turbid or geometric atmosphere and canopies. A photon is tracked from birth (emission or penetration within medium) to death (absorption or escape from medium), with scattering based on probabilistic wave 
matter interactions. Millions of simulations describe spectral, directional and spatial behaviors. Ray tracing is used to assess the influence of multiple scattering on spatial aggregation and angular dynamics, over heterogeneous and non isothermal land surfaces, [127, 150, 151].

\subsubsection{Inversion Methods}

Retrieving variables from measurements is an inverse problem. Given a set of $m$ measurements $M$ for a physical system, with $k$ known parameters $K$ and $p$ unknown parameters $P$ to be retrieved, direct $F$ and inverse $F^{-1}$ problems are written [152]:

$$
\left[\begin{array}{c}
M_{1} \\
\vdots \\
M_{m}
\end{array}\right]=F\left(\left[\begin{array}{c}
P_{1} \\
\vdots \\
P_{p}
\end{array}\right],\left[K_{1} \cdots K_{k}\right]\right) \Longleftrightarrow\left[\begin{array}{c}
P_{1} \\
\vdots \\
P_{p}
\end{array}\right]=F^{-1}\left(\left[\begin{array}{c}
M_{1} \\
\vdots \\
M_{m}
\end{array}\right],\left[K_{1} \cdots K_{k}\right]\right)
$$

Inversion is possible if there are more independent equations than unknowns $(m \geq p)$. Direct inversion analytically writes the inverse problem. This is possible for simple radiative transfer equations (Section 10.4.2), but not for most simulation models (Section 10.4.3). For the latter, indirect inversion numerically sets parameters such as simulations agree with observations [153]. It has been improved for accuracy and rapidity, by calibrating neural networks, lookup tables, genetic algorithms or regression trees $[152,154]$. Inversion can be a well posed problem, when solving an overdetermined equation system using optimization techniques. However, it is usually an ill posed problem, with several parameters to be constrained from few observations. Proposed solutions use a priori information about soil and vegetation properties, or parameter ranges $[152,155,156]$.

Inversion over the TIR domain is not as developed as over the solar domain. This results from (1) additional micrometeorological complex influences, and (2) the lack of high resolution data. Atmospheric simulation models have been inverted calibrating neural networks [51], SW and DA methods (Eq. 10.9) [125, 126], or the atmospheric radiative transfer equation (Eq. 10.6) [157, 158]. Over land surfaces, simulation models have been assessed in the forward mode [72-74, 77, 144]. No investigation was found about their indirect inversion, but they can serve as references for parameterizing simple radiative transfer equations which are directly invertible. Thus, various formulations have been assessed for the soil and vegetation radiative transfer equation (Eq. 10.10), optionally accounting for multiple scattering and non linearity $[68,71,118,119,127]$. Further, inverting simple radiative transfer equations is often an ill posed problem. For instance, inverting the composite surface radiative transfer equation (Eq. 10.7) from $N$ multispectral observations includes $N$ emissivities and radiometric temperature. Similarly, inverting the soil and vegetation radiative transfer equation (Eq. 10.10) or linear kernel driven approaches (Eq. 10.11) from multiangular observations requires angular parameters: ensemble, soil and vegetation emissivities; vegetation transmittance. 


\subsection{Assessing Modeling Tools and Inversion Methods}

Modeling tools and inversion methods have been assessed experimentally through validation exercises, and theoretically via sensitivity studies.

Validation exercises have been conducted over databases collected in the framework of various international programs such as FIFE [159], EFEDA [160], HAPEX [161], ReSeDA [97], JORNEX [162], FLUXNET [163], DAISEX [164], SALSA [165], SMACEX [166]. Assessments over these various datasets allow accounting for different biomes and climates. Some exercises were ground based [73, 104, 145]. Most of them were airborne based [94, 96, 103, 157, 167-169,170-174], for assessments in actual conditions by reducing spatial heterogeneity effects. Few validations were conducted using spaceborne observations with hectometric resolutions [175179]; and with kilometric ones over areas almost homogeneous [180-182]. Original exercises based on classifications were designed for kilometric scale heterogeneities [126, 183], while new improvements for the solar domain should be implemented over the thermal one [184]. Complementary to validations, intercomparisons are now feasible thanks to multisensor missions such as Terra. This allows accounting for larger panels of environmental situations [158].

Validations and intercomparisons are also performed using simulated datasets. This allow considering more conditions than measured datasets, and focusing on physics modeling without measurement intrinsic errors [81, 82, 126, 185]. Simulated datasets are necessary when dealing with elaborated temperatures: aerodynamic, soil and vegetation, sunlit and shaded components, and canopy temperature profile $[68,71,73,76,118]$. Indeed, validating the latter using measured datasets is not trivial, since the corresponding ground-based measurements are difficult to implement.

Additionally to validations and intercomparisons, sensitivity studies allow assessing information requirements such as accuracies on remotely sensed information, medium structural and radiative properties. Examples are (1) accuracy on atmospheric status for retrieving brightness temperature [171, 178], (2) accuracy on observations, atmospheric status and land use for recovering ensemble emissivity and radiometric temperature [12, 157, 158, 169, 182, 186-188], (3) accuracy on canopy structural parameters and radiative properties for deriving soil and vegetation temperatures $[68,118,189]$. Finally, sensitivity studies of simulation models provide valuable information about the pertinent parameters for inversion [73, 76], with innovative approaches over the solar domain based on adjoint models (Baret et al., this issue).

\subsection{Current Capabilities and Future Directions}

From the basic materials presented before, we focus now on current investigations, via an increasing temperature complexity. Success and failures suggest future directions. 


\subsubsection{Surface Brightness Temperature}

Surface brightness temperature is derived from that at the sensor level by inverting modeling tools for atmosphere. It is simulated using modeling tools for land surfaces. In both cases, these tools are simple radiative transfer equations or simulation models.

\subsubsection{Atmospheric Radiative Regime and Related Corrections}

Atmospheric corrections for the retrieval of surface brightness temperature can be performed inverting simulation models, via the calibration of the atmospheric radiative transfer equation (Eq. 10.6) for a given atmosphere [12,81, 157, 158, 171, 172, 177, 178]. An operational context faces two challenges: reducing computation time to process millions observations, and accurately characterizing the atmospheric status.

To reduce by a third-order computation time for simulation models without accuracy degradation, [190] implemented correlated-K methods, by quickly integrating waveband atmospheric absorption and emission. Predictor based models accurately compute the latter for a range of reference profiles, to next differencing current ones and nearest predictors [191]. Multilayer computation based on water vapor continuum absorption can replace simulation models, with an accuracy degradation lower than $1 \mathrm{~K}$ [81]. Computation time can also be reduced via inversion by including a range of atmospheres into the simulation set. Expressing transmittance and upwelling radiance of Eq. 10.6 from atmosphere water vapor content and mean temperature yields an accuracy degradation lower than 2 K [180]. Neural networks can replace Eq. 10.6 considering atmospheric profiles and view zenith angle, with an accuracy degradation lower than $0.5 \mathrm{~K}[186,192]$.

The atmospheric status can be well documented using ancillary information: measured profiles allow reaching a $1 \mathrm{~K}$ accuracy $[171,172,177,178]$, but meteorological networks are not dense enough for regional inversion. One alternative is profile simulation from meteorological models [193, 194]. Such information is soon available with a $3 \mathrm{~h}$ sampling, and a $0.25^{\circ}$ latitude/longitude griding to be re-sampled to sensor resolutions via interpolation procedures [12, 195]. The relief influence is handled using digital elevation models, now available with decametric resolutions and metric accuracies [196]. Also, the TIR observations to be corrected can inform about the atmospheric status. Atmosphere absorption and emission can be retrieved from multispectral and hyperspectral observations, using variabilities of atmospheric properties [80, 197]. Thus, water vapor content was adjusted from ASTER multispectral observations, such as emissivity spectrum is flat over vegetation or water [185]. It was also inferred from the ATSR-2 SW channels with a $0.2 \mathrm{~g} . \mathrm{cm}^{-2}$ accuracy, using the SWVCR which relies on the spatial variability of SW surface brightness temperatures [198].

Solar or TIR observations collected onboard the same platform also provide coincident information about the atmospheric status. [199] expressed water vapor 
content as a polynomial of MODIS near infrared radiance ratios, with a $0.4 \mathrm{~g} . \mathrm{cm}^{-2}$ accuracy. Atmospheric sounders allow inferring profiles of temperature and water vapor density, using Eq. 10.6 or neural networks [3, 4]. Previous sounders such as TOVS permitted to reach a $0.4 \mathrm{~g} . \mathrm{cm}^{-2}$ accuracy on water vapor content [200]. New sounders such as IASI [201], with finer spectral samplings and spatial resolutions, should provide accuracies better than $1 \mathrm{~K}$ and $10 \%$ for atmospheric profiles of temperature and humidity.

\subsubsection{Land Surface Radiative Regime and Related Measurements}

Surface brightness temperature is simulated using simple radiative transfer equations or simulation models. The former provide easy and efficient solutions for assimilating TIR remote sensing data into land process models. The latter are fine and accurate solutions for understanding well TIR remotely sensed measurements.

To constrain land process model parameters, surface brightness temperature can be simulated using simple radiative transfer equations coupled with SVAT models. [39] coupled the composite surface radiative transfer equation (Eq. 10.7) with a crop and a one source SVAT model. The latter calculated ensemble radiometric temperature by closing surface energy budget. R-emissivity was estimated using the SAIL TIR version of [136], documented by the crop model for vegetation structural parameters. Similarly, [67] coupled the soil and vegetation radiative transfer equation (Eq. 10.10) with a two source SVAT model. The latter calculated soil and vegetation temperatures by closing energy budget for each, while setting soil and vegetation emissivities to nominal values.

Calculating surface brightness temperature from simulation models requires information about vegetation structure (row crop, LAI, LIDF, cover fraction), soil and vegetation radiative properties (emissivity, reflectance), and thermal regime (canopy temperature distribution). The latter can be derived from a SVAT model, which solves local energy budget according to meteorological conditions (solar position, wind speed, air temperature), vegetation status (leaf stomatal resistance), and soil moisture. Then, simulation models mimic the radiative regime using more or less complex descriptions of the thermal regime: a unique vegetation temperature [73], soil and vegetation temperatures with optional sunlit and shaded components [74, 137], additional vegetation layer temperatures for specific crops [145], or canopy temperature profile [78].

Simulation models are currently under development, verification and analysis [73, 74, 76, 78, 144, 145]. Current investigations focus on spectral behaviors [120], but especially on directional effects which allow normalizing multiangular observations (Fig. 10.3). For instance, [58, 72] angularly normalized water stress indices over row structured crops. Similarly, [202] normalized across track observations from sun-view geometry effects, for a daily monitoring at the continental scale. 


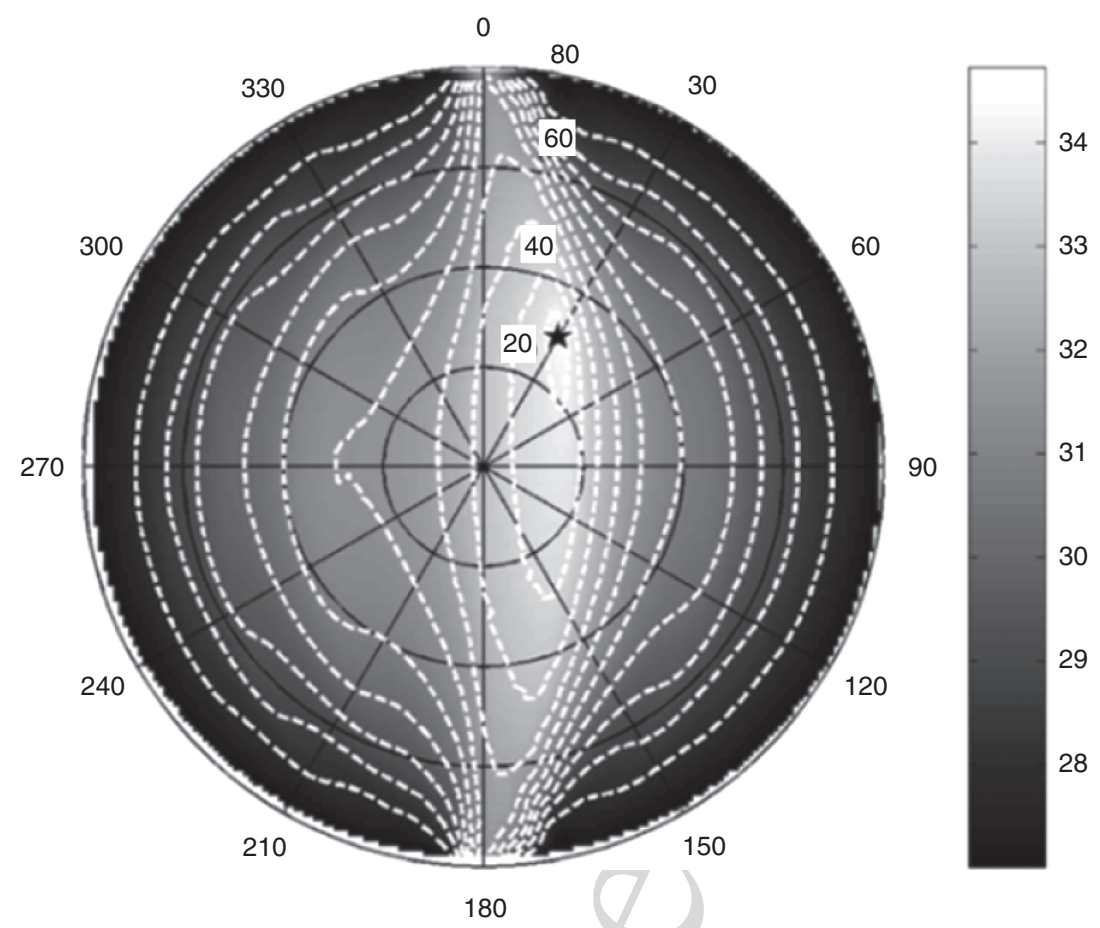

Fig. 10.3 Simulating measured brightness temperature over a maize canopy in row structure, with a resulting angular dynamic about $8 \mathrm{~K}$ [73]. Black star indicates the solar direction. The brightness temperature maximum value is located in the solar direction. However, this hot spot effect is not systematical (Section 10.6.4.)

\subsubsection{Partial Conclusions}

The various methods developed to perform atmospheric corrections are of interest, since they were designed for optimizing the collected information according to sensor configurations. Measured or simulated profiles are tributary to their representativeness, and coincident information relies on strong assumptions. Despite these limitations, significant progresses were made the last decades, with accuracies now close to $1 \mathrm{~K}$. Current investigations focus on refinements rather than new developments.

Simulating brightness temperature is ongoing for describing brightness temperature measurements, according to the various land surface behaviors: geometric like, radiative transfer like, or both. Validation results emphasized good performances with accuracies close to $1 \mathrm{~K}$, though significant documentations are required about thermal regime, medium structure and radiative properties. Such simulation models will be of interest for future designs of inversion methods, conjointly to the solar domain (Section 10.4.4). 


\subsubsection{Ensemble Emissivity and Radiometric Temperature}

Ensemble radiometric temperature is derived by directly inverting composite surface radiative transfer equation (Eq. 10.7), or indirectly inverting simulation models via differencing equations (Eq. 10.9). The first way is two-step based and requires previous atmospheric corrections. The second way is one-step based by simultaneously correcting atmosphere and surface effects. In both cases, performances depend on characterizing these effects. Inverting Eq. 10.7 is an ill posed problem, with $N$ equations from channel measurements and $N+1$ unknowns being channel emissivities and radiometric temperature. Proposed solutions consist of adding a $N+1$ equation. They are reported here via an increasing amount of information, according to the spectral, directional and temporal dimensions.

\subsubsection{Single-Channel TIR Instantaneous Observations}

Radiometric temperature is derived from single channel observations using two step approaches. After atmospheric corrections, inverting the composite surface radiative transfer equation (Eq. 10.7) requires estimating waveband emissivity. The latter is inferred using in-situ observations, nominal values proposed by literature, or solar remotely sensed observations. This have been investigated for ground based and airborne sensors during field experiments, and for spaceborne sensors such as the Landsat TM series.

Considering ensemble emissivity increases with vegetation amount, it can be linked to NDVI [203], or to cover fraction (Eq. 10.8) if neglecting spatial variabilities for soil and vegetation emissivities [177, 199]. However, low correlations were observed between AVHRR emissivities and cover fraction [188]; and between ASTER broadband emissivity and MODIS solar albedo [46]. Indeed, the link between emissivity and vegetation amount depends on canopy structure, cavity effect, and optical properties of soil and vegetation [136]. Besides, emissivity may decrease with the vegetation amount, according to the type of soil and the vegetation water status [120].

Good results were reported with TM and DAIS (1 K over semi-arid agricultural areas $[174,177])$, but the use of in situ information at the local scale raises the question of method applicability. A promising way is using additional MIR data, which contain information on water content. For optimizing the temporal monitoring, another possibility is deriving single channel emissivity from multispectral ones, by conjointly using different sensors such as Landsat and ASTER. However, this is tributary to the temporal stability of surface conditions between consecutive satellite overpasses.

\subsubsection{Dual-Channel and Dual-Angle TIR Instantaneous Observations}

Radiometric temperature is recovered from dual channel and dual angle observations using SW and DA one step approaches, which require accounting well for 
atmospheric and surface effects $[125,126]$. Most investigations deal with the SW method, since multispectral observations are more usual than multiangular ones.

Various versions have been proposed for Eq. 10.9: linear or quadratic forms ( $\mathrm{B}=0$ or $\mathrm{B} \neq 0$ ), optional inclusion of emissivity $(\mathrm{C}=0$ or $\mathrm{C} \neq 0, \mathrm{D}=0$ or $\mathrm{D} \neq 0$ ), expressing coefficients from atmospheric water vapor content. Larger freedom degrees perform better $[125,126,174,183,204]$. Wavebands around 11 and $12 \mu \mathrm{m}$ are the most appropriate for SW and DA assumptions, since they correspond to low variations of emissivity, spectrally and spatially [172, 174]. Calibration relies on simulations from emissivity spectral libraries and atmospheric radiative transfer [82, 125, 126, 204]. Operational use requires documentation. Atmospheric water vapor content is inferred from climatological database [183], the SWVCR [198] or near infrared radiance ratios [199]. Emissivities are derived from classifications [181, 182, 205], or from Eq. 10.8 with nominal values for soil and vegetation emissivities [172, 199].

Several validation exercises reported accuracies better than $1 \mathrm{~K}$. Excellent results were obtained from TIMS without a priori information [172]. Using classification based knowledge of emissivity can perform well [181, 182], though significant subclass variabilities were observed [206, 207]. However, a $1 \mathrm{~K}$ accuracy usually requires local information on surface conditions for emissivity effects. Further, the lack of such information can induce errors up to $3 \mathrm{~K}$ [125, 126, 174, 183, 199].

\subsubsection{Multispectral and Hyperspectral TIR Instantaneous Observations}

Radiometric temperature is derived from multispectral and hyperspectral observations using two step approaches. After atmospheric corrections, the ill posed problem can be solved using either a priori information, or the spectral variability captured over the whole TIR range. This last possibility is very different from the two channel SW differencing which aims at avoiding emissivity variations.

For multispectral observations, the NEM approach sets maximum emissivity to a nominal value [208], where the latter can be derived from Eq. 10.8 using a priori information about soil and vegetation emissivities [173]. The adjusted ANEM relies on land use [168, 170], and the MIR NEM is extended to MIR observations [209]. Rather than using a priori information, other approaches aim at benefiting the variability captured from multispectral and hyperspectral data, the latter providing finer spectral samplings. The TES algorithm derives minimum emissivity from the spectral variations, via an empirical relationship verified over most land surfaces for the TIR and the MIR domains [104, 157, 210-212]. Capturing larger variabilities with hyperspectral data increase TES accuracy up to $0.5 \mathrm{~K}$ [104]. To derive absolute emissivity from relative spectral variations, the alpha residuals logarithmically linearize Planck's equation, with an optional improvement based on Taylor expansion for hyperspectral observations [213]. Taylor expansion also provide derivative approaches, such as the "Grey Body" method [123]. Finally, multispectral and hyperspectral observations are useful for deriving broadband emissivity via NTB conversions [52, 54, 207, 214]. 


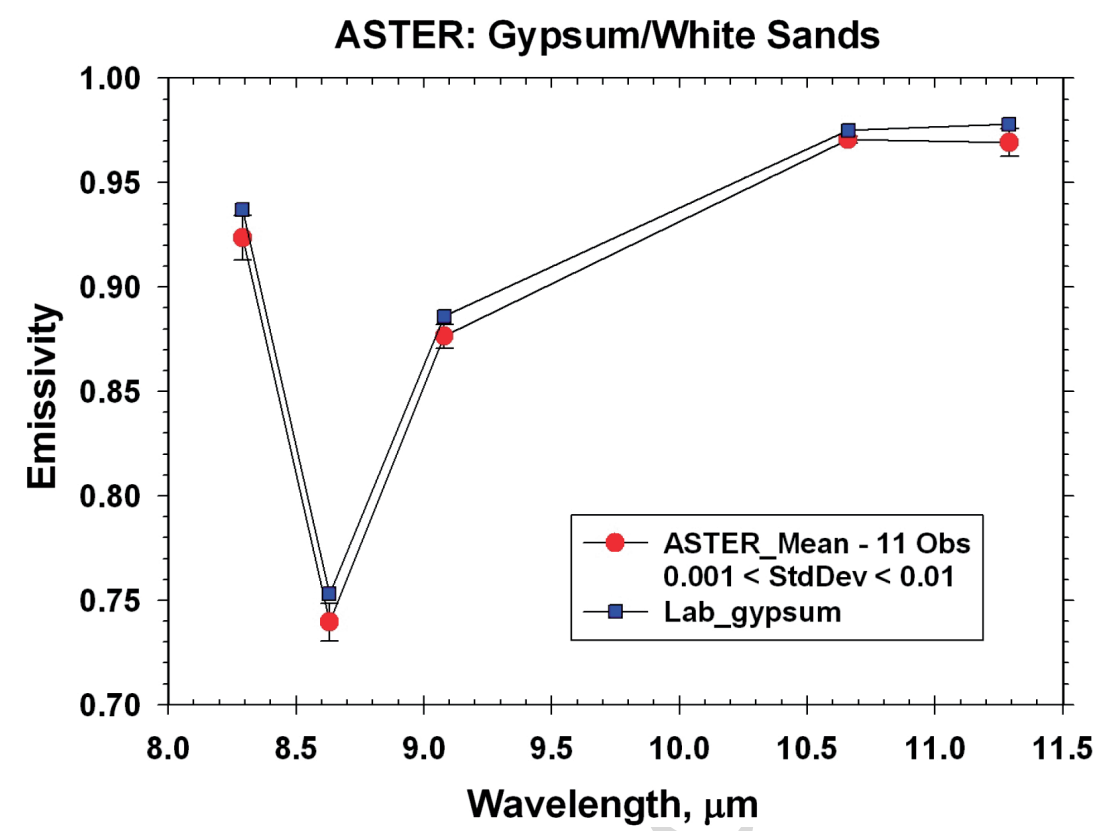

Fig. 10.4 Validation, against sample based laboratory measurements (squares), of ASTER/TES emissivity retrievals (circles), for eleven days over a gypsum site at the White Sands National Monument in New Mexico. TES derived emissivity spectra were averaged over the 11 acquisitions, where the corresponding standard deviation ranges from $10^{-3}$ to $10^{-2}$. (From [265].)

Several validation exercises reported $1 \mathrm{~K}$ accuracies for NEM, with or without a priory information $[168,170,173]$. Good results were obtained for the TES algorithm (Fig. 10.4), with accuracies better than 0.01 on emissivity [176] and $1 \mathrm{~K}$ on temperature [173]. Similar performances were reported by [158] when intercomparing ASTER/TES and MODIS/TISIE/retrievals (Fig. 10.5, the TISIE concept is presented below).

\subsubsection{Multispectral MIR and TIR Consecutive Observations}

Solving the ill-posed problem to invert Eq. 10.7 is also possible using temporal series from geostationary or sunsynchronous daytime/nighttime observations. Assuming emissivity is stable between consecutive observations yields more equations than unknowns. Then, investigations rely on using TIR observations only [215], or MIR/TIR observations [12, 186, 188, 216].

TTM is a two step approach for inverting Eq. 10.7 over TIR consecutive observations [217]. Assuming surface emissivity is constant yields $2 N$ equations for $N+2$ unknowns: $N$ channel emissivities and two radiometric temperatures. Then, two channels are enough for solving the ill-posed problem. TTM performs better 

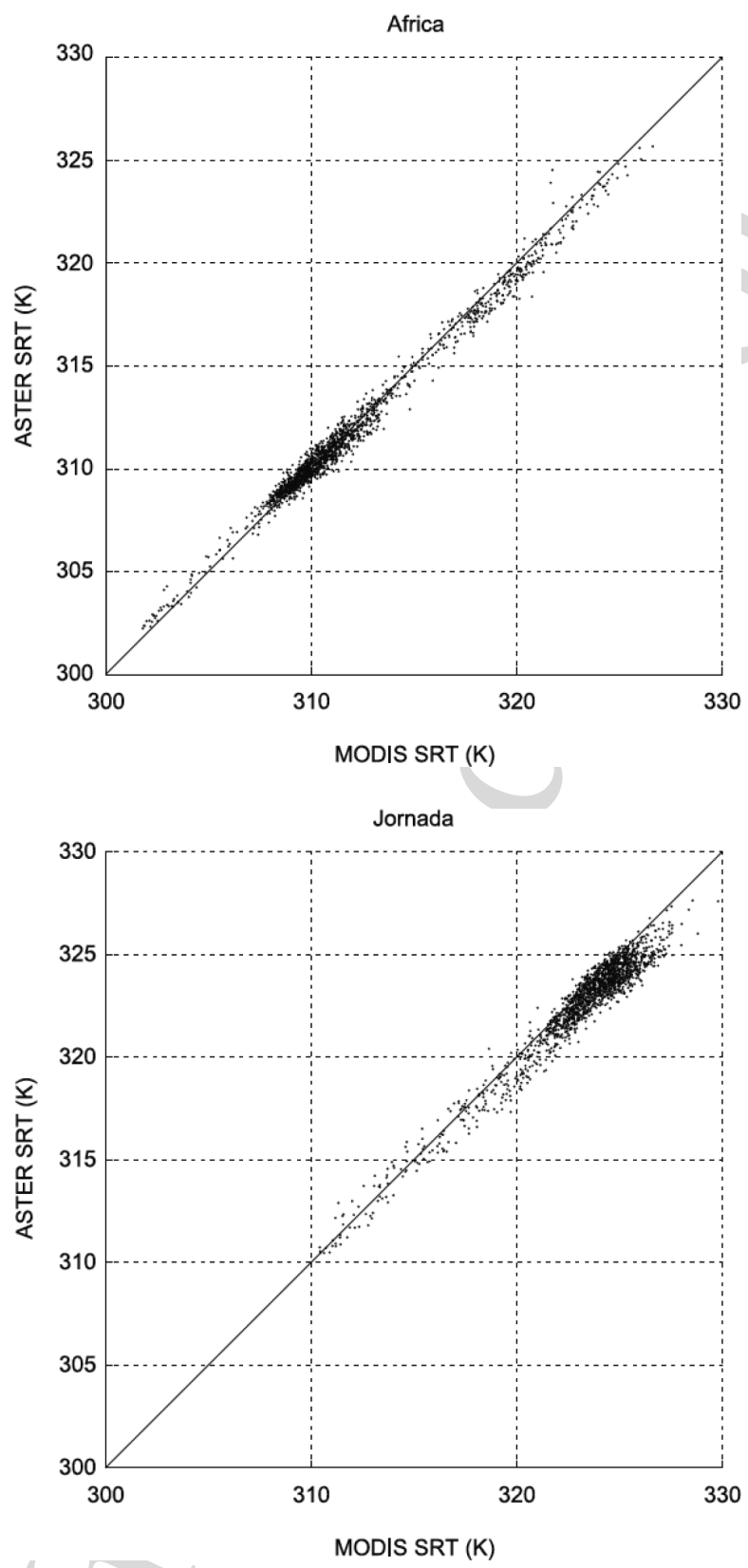

Fig. 10.5 Intercomparison, over a Savannah landscape (Africa) and a semiarid rangeland (Jornada), of surface radiometric temperature retrievals from the MODIS/TISIE and ASTER/TES algorithms. Differences were lower than 0.9 K. (From [158].) 
with the SEVIRI finest temporal sampling, and with observations near daily temperature extrema [187, 215]. TISIE is a two step approach for inverting Eq. 10.7 over TIR and MIR daytime/nighttime observations. Raising emissivity ratios to specific power yields relative variations free from radiometric temperature. Assuming TISIE are stable between consecutive observations, MIR r-emissivities can be retrieved, and next TIR ones. Various TISIE versions were designed for AVHRR, MODIS, SEVIRI [12, 186, 188, 218]. Day Night Pair is a one step approach for inverting both Eqs. 10.6 and 10.7 over TIR and MIR daytime/nighttime observations. The system of $2 N$ equations with $N+2$ unknowns can be solved with $k$ additional unknowns, as long as $k \leq N-2$. Thus, the 7 MODIS channels allow recovering five unknowns about atmospheric and surface effects [216].

The accuracies reported for these methods range from 0.5 to $2.5 \mathrm{~K}$, and are slightly worse for TTM. They correspond to sensitivity studies for TTM and TISIE [186-188], to validation exercises over various study sites for Day Night Pair (Fig. 10.6) [181, 182], and to intercomparisons against ASTER/TES retrievals for TISIE [158].

\subsubsection{Partial Conclusions}

Radiometric temperature is derived by indirectly inverting simulation models through differencing equations (Eq. 10.9), or directly inverting simple radiative transfer equations (Eqs. 10.6 and 10.7). Solving the ill-posed problem depends on

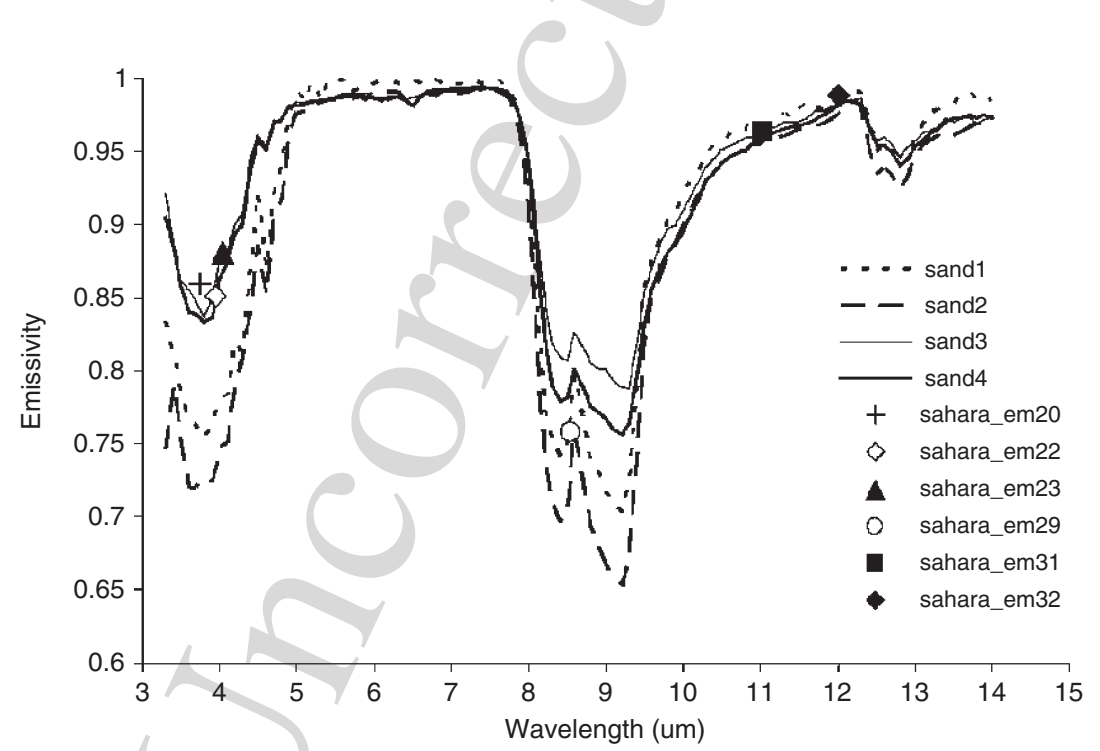

(a)

Fig. 10.6 Validation, against sample-based laboratory spectra (lines), of Day Night Pair-based MODIS retrievals over the Sahara Desert (points). (From [182].) 
the available remote sensing information. A priori information is needed to obtain good results with instantaneous single channel or dual channel / dual angle data. It can be avoided with more remote sensing information: instantaneous TIR and MIR data, instantaneous multispectral TIR data, or temporal series with dual channel data. Similarly, more surface and atmospheric parameters can be recovered with a larger amount of remotely sensed information.

Reported accuracies have increased these last years, and are now closer to that required for further applications, i.e., $1 \mathrm{~K}$. For instance, differences between retrievals from ASTER/TES and MODIS/TISIE were found lower than $0.9 \mathrm{~K}$, though both methods differ in terms of using spectral, directional and temporal information [158]. However, ASTER/TES, MODIS/Split Window and MODIS/Day Night Pair were found very different over Northern America [206]. Current efforts are refinements rather than new concepts: desegregation methods should allow benefiting the synergy between IASI hyperspectral and AVHRR kilometric sensors onboard METOP. Then, the next challenge is retrieving more elaborated temperatures, discussed below.

\subsubsection{Aerodynamic Temperature}

Aerodynamic temperature $T_{\text {aero }}$ and thermal roughness length $z_{o h}$ are equivocal variables which cannot be directly recovered from remote sensing (Section 10.4.1). Therefore, investigations have aimed at substituting aerodynamic for radiometric temperature $T_{r a d}$, by parameterizing a correcting factor in the sensible heat flux expression (Eq. 10.1).

The physical meaning of sensible heat flux (Eq. 10.1) can be preserved using the multiplicative factor $\frac{T_{\text {aero }}-T_{\text {air }}\left(z_{\text {ref }}\right)}{T_{\text {rad }}-T_{\text {air }}\left(z_{\text {ref }}\right)}$, empirically expressed from LAI [162]. However, studying this factor from simulations and measurements for growing sparse vegetation showed significant variations according to meteorological and surface conditions [63].

The correcting factor can also be included in the $k B^{-1}$ parameter (Eq. 10.2), which is then called thermal $\mathrm{kB}^{-1}$ [113]. It includes corrections for (1) the difference between thermal and mechanical roughness lengths, and (2) the difference between radiometric and aerodynamic temperatures. According to environmental conditions, thermal $\mathrm{kB}^{-1}$ varies from a vegetation type to another, and up to $100 \%$ in relative terms $[113,219]$. Parameterizations based on near surface wind speed and temperature gradients depend on sensible heat flux [220]. Overall, formulating the thermal $\mathrm{kB}^{-1}$ seems almost impossible, since it is driven by several factors which vary in time and space: vegetation structure and water stress, meteorological conditions, canopy temperature profile and solar position [221-229].

A potential way for characterizing the $\mathrm{kB}^{-1}$ parameter would be multiangular TIR remote sensing [230]. However, using this information for deriving soil and vegetation temperatures seems more pertinent. First, these temperatures are 
functionally equivalent to aerodynamic temperature (Eq. 10.3). Second, they provide information for monitoring vegetation photosynthesis and soil respiration.

\subsubsection{Directional Emissivity and Soil/Vegetation Temperatures}

Single directional radiometric temperature can be split into soil and vegetation components by closing energy balance for each. However, this relies on strong assumptions about vegetation water status [231-233]. The promising approach is then using multiangular TIR observations [20, 68, 71, 118, 119, 189]. No literature was found about retrieving soil and vegetation temperatures by inverting simulation models over multiangular data. Nevertheless, such models have been used for parameterizing the soil and vegetation radiative transfer equation which is directly invertible (Eq. 10.10). These parameterizations were designed considering the [8-14] $\mu \mathrm{m}$ spectral range.

\subsubsection{Parameterizing the Soil/Vegetation Radiative Transfer Equation}

Inverting Eq. 10.10 requires estimating the involved parameters (ensemble emissivity $\varepsilon\left(\lambda_{j}, \theta\right)$, vegetation transmittance $\tau^{c a n}(\theta)$, and vegetation fraction of emitted radiance $\omega\left(\theta, \varepsilon_{v e g}\left(\lambda_{j}\right)\right)$ ), with optional simplifications for easier use. Various complexity degrees have been proposed, listed in Table 10.3 (P1-P8). This yields introducing two new parameters. Hemispherical gap fraction $\sigma_{f}$ is directional gap fraction integrated over illumination angles, to account for atmospheric thermal irradiance down to the soil via the vegetation. The cavity effect coefficient $\alpha$ is the ratio of canopy to vegetation hemispherical-directional reflectance, to account for radiation trapping within the canopy.

The finest parameterization (P1), proposed by [118], accounts for multiple scattering and cavity effect. The latter, which does not depend on LAI, was previously calculated as a function of LIDF and view zenith angle, by using the probabilistic simulation model from [139]. Similarly, [127] introduced effective directional gap $F_{\text {soil }}^{\text {eff }}(\theta)$ and cover $F_{\text {veg }}^{\text {eff }}(\theta)$ fractions $(\mathrm{P} 2) . F_{\text {soil }}^{\text {eff }}(\theta)$ included single scattering of soil emission by vegetation. $F_{v e g}^{e f f}(\theta)$ included single scattering of vegetation emission by soil and vegetation. Half complex parameterizations (P3-P5) account for multiple scattering, with optional linearizations $[68,71]$. The simplest parameterizations (P6-P8) do not account for cavity effect nor multiple scattering. They differ by their linearization degrees, and their assumptions about soil and vegetation emissivities $[71,119,189]$.

Some of these parameterizations were assessed in direct mode for simulating directional ensemble emissivity and radiometric temperature [68]. The conclusions were apart from simplest versions, most provided close results for directional canopy emissivity, with discrepancies lower than 0.01 . For radiometric temperature, all provided similar results, with differences lower than $1 \mathrm{~K}$. Next, differences 
Table 10.3 Listing of existing parameterizations (P1-P8) for the soil and vegetation radiative transfer equation (Eq. 10.10), with a decreasing complexity. The spectral dependence was removed since these parameterizations were designed considering the [8-14] $\mu \mathrm{m}$ spectral range. Labels $f_{i}$ refer to specific functions proposed by the corresponding references. The dependence on LAI and LIDF is implicitly included into directional gap and cover fractions $F_{\text {soil }}(\theta)$ and $F_{v e g}(\theta)$, the cavity effect coefficient $\alpha(\theta)$, and hemispherical gap fraction $\sigma_{f}$ [68].

\begin{tabular}{|c|c|c|}
\hline & & $\begin{aligned} & \text { Standard formulation } \\
\varepsilon(\theta) B\left(T_{\text {rad }}(\theta)\right)= & \tau^{\text {can }}(\theta) \varepsilon_{\text {soil }} B\left(T_{\text {soil }}\right)+\omega\left(\theta, \varepsilon_{\text {veg }}\right) B\left(T_{\text {veg }}\right)\end{aligned}$ \\
\hline Label & From & Formulations \\
\hline $\mathrm{P} 1$ & [118] & $\begin{array}{ll}\varepsilon(\theta)=f_{3}\left(F_{\text {soil }}(\theta), \varepsilon_{\text {soil }}, \varepsilon_{\text {veg }}, \sigma_{f}, \alpha(\theta)\right) & \text { Accounts for } \\
\tau^{\text {can }}(\theta)=F_{\text {soil }}(\theta) & \text { multiple scattering } \\
\omega\left(\theta, \varepsilon_{\text {veg }}\right)=f_{4}\left(F_{\text {soil }}(\theta), F_{\text {veg }}(\theta), \varepsilon_{\text {soil }}, \varepsilon_{\text {veg }}, \sigma_{f}, \alpha(\theta)\right) & \text { and cavity effect }\end{array}$ \\
\hline $\mathrm{P} 2$ & [127] & $\begin{array}{l}\varepsilon(\theta)=F_{\text {soil }}^{\text {eff }}(\theta) \varepsilon_{\text {soil }}+F_{\text {veg }}^{e f f}(\theta) \varepsilon_{\text {veg }} \\
\tau^{\text {can }}(\theta)=F_{\text {soil }}^{\text {eff }}(\theta) \\
\omega\left(\theta, \varepsilon_{\text {veg }}\right)=F_{\text {veg }}^{\text {eff }}(\theta) \varepsilon_{\text {veg }} \\
F_{\text {soil }}^{\text {eff }}(\theta)=f_{1}\left(F_{\text {veg }}(\theta), \sigma_{f}\right) \\
F_{\text {veg }}^{e f f}(\theta)=f_{2}\left(F_{\text {soil }}(\theta), \sigma_{f}\right)\end{array}$ \\
\hline P3 & {$[68]$} & $\begin{array}{l}\varepsilon(\theta)=f_{5}\left(F_{\text {soil }}(\theta), F_{\text {veg }}(\theta), \varepsilon_{\text {soil }}, \varepsilon_{\text {veg }}, \sigma_{f}\right) \\
\tau^{\text {can }}(\theta)=f_{6}\left(F_{\text {soil }}(\theta), \varepsilon_{\text {soil }}, \varepsilon_{\text {veg }}, \sigma_{f}\right) \\
\omega\left(\theta, \varepsilon_{\text {veg }}\right)=f_{7}\left(F_{\text {soil }}(\theta), F_{\text {veg }}(\theta), \varepsilon_{\text {soil }}, \varepsilon_{\text {veg }}, \sigma_{f}\right)\end{array}$ \\
\hline P4 & [71] & Linearizing P3 considering $B(T) \approx \sigma T^{4}$ \\
\hline P5 & & Linearizing P3 considering $B(T) \approx \sigma T$ \\
\hline P6 & [119] & $\begin{array}{l}\varepsilon(\theta)=F_{\text {soil }}(\theta) \varepsilon_{\text {soil }}+F_{\text {veg }}(\theta) \varepsilon_{\text {veg }} \\
\tau^{\text {can }}(\theta)=F_{\text {soil }}(\theta) \\
\omega\left(\theta, \varepsilon_{\text {veg }}\right)=F_{\text {veg }}(\theta) \varepsilon_{\text {veg }}\end{array}$ \\
\hline P7 & [71] & Linearizing P6 considering $B(T) \approx \sigma T$ \\
\hline P8 & & Simplifying P7 considering $\varepsilon_{v e g}=\varepsilon_{\text {soil }}=1$ \\
\hline
\end{tabular}

decreased with atmospheric irradiance which compensates emission (Eq. 10.7). However, this is minor under clear sky conditions, with irradiance lower than 30 W. $\mathrm{m}^{-2}$ between 8 and $14 \mu \mathrm{m}$ [234]. Finally, [127] observed analytical formulation P2 significantly diverged from a ray tracing reference when soil and vegetation emissivities were very different.

\subsubsection{Inverting the Soil/Vegetation Radiative Transfer Equation}

The various parameterizations reported above have been assessed in inverse mode considering dual angle observations, nadir and 45 or $55^{\circ}$ off nadir. Given soil and vegetation emissivities, dual angle measurements allow retrieving component temperatures. Off nadir angles above $45^{\circ}$ are required to capture large angular dynamics 
and reduce observation errors [108, 109, 119, 144, 235-237]. Dual angle observations at 0 and $55^{\circ}$ correspond to the ATSR suite viewing configuration.

Converging conclusions were reported about the documentation requirements for canopy structural parameters. Poorly estimating LIDF can result in errors on temperatures up to $1 \mathrm{~K}$ [118]. LAI must be known within 5\% (respectively $10 \%$ ) for a $0.5 \mathrm{~K}$ accuracy on vegetation (respectively soil) temperature [118, 119]. Similarly, a $7-8 \%$ relative error on directional cover fraction can induce errors on soil and vegetation temperatures from 1 to $3 \mathrm{~K}$ [189]. Such recommendations have to be compared with current accuracies on LAI retrievals from solar remote sensing, i.e., around $20 \%$ [238].

Diverging conclusions were reported about the documentation requirements for canopy radiative properties, the parameterization degree to be considered, and the performances. First, [118] concluded a 0.01 accuracy is necessary for soil and vegetation emissivities, whereas [71] claimed using unity values has no consequence. Second, [71, 119] concluded simple parameterizations similarly performed than complex ones, while multiple scattering and cavity effect can be neglected. Conversely, [68] reported it is necessary accounting at least for multiple scattering (Fig. 10.7). Third, [68] concluded a $1 \mathrm{~K}$ accuracy can be reached on both
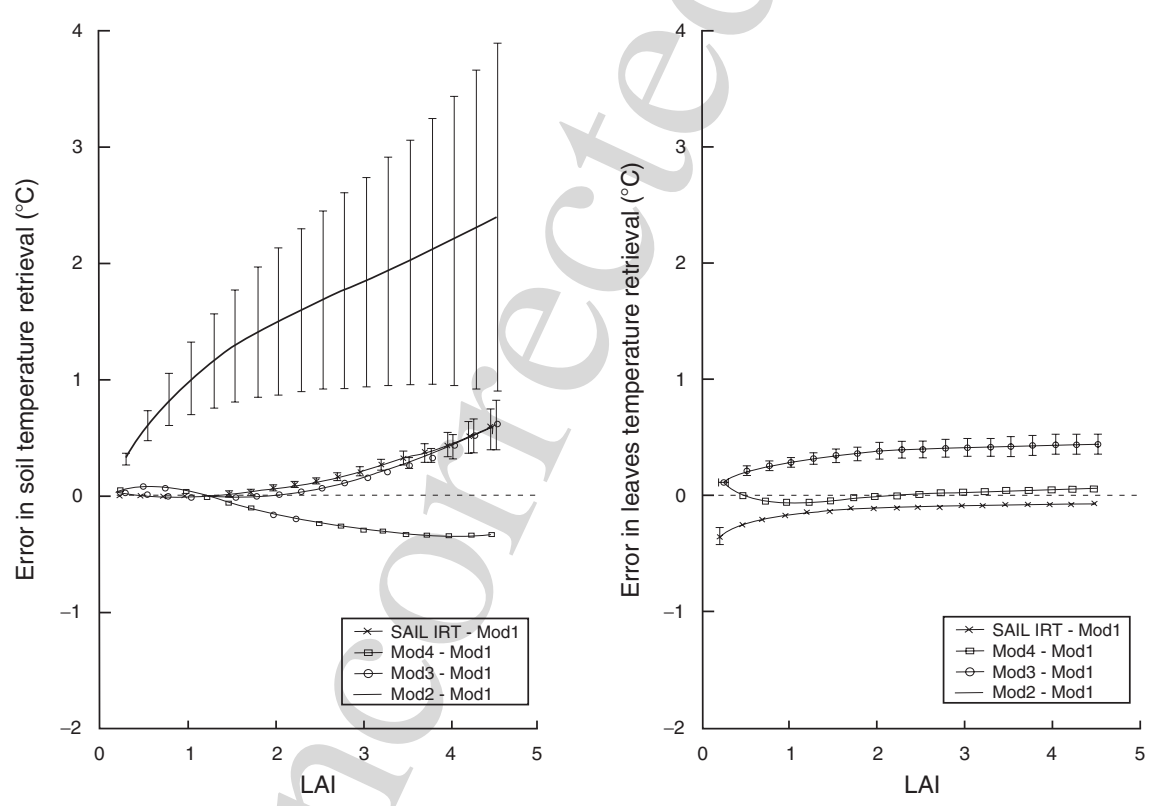

Fig. 10.7 Performance intercomparison for the different parameterizations listed in Table 10.3. Mean errors on soil (left) and vegetation (right) temperature retrievals are plotted as functions of LAI, along with standard deviations (bars). Reference "Mod 1" is the probabilistic simulation model of [139]. "SAIL IRT" is the TIR version of the SAIL radiative transfer model from [68]. "Mod 2" is the parameterization P6, "Mod 3" the P3 and "Mod 4" the P1. (From [68].) 
temperatures, and better for vegetation than soil; whereas [71] reported lower errors for soil $(<2 \mathrm{~K})$ than vegetation $(<4 \mathrm{~K})$.

\subsubsection{Partial Conclusions}

Parameterizing the soil and vegetation radiative transfer equation still is in debate, as is the required documentation. Additionally to parameters to be well estimated, both structural (LAI, LIDF, directional gap and cover fractions, hemispherical gap fraction, cavity effect), and radiative (ensemble emissivity and radiometric temperature), inversion includes emissivity and radiometric temperature for soil and vegetation.

When focusing on finer temperatures such as sunlit and shaded components for soil and vegetation, or canopy temperature profile, complex simulation models with additional unknowns have to be considered (Section 10.4.3). Then, attractive modeling tools are linear kernel driven approaches for accuracy and feasibility (Section 10.4.2). Such a tool have been inverted and validated against multidirectional observations, with promising results about the potential for adjusting the captured angular dynamic [103, 128].

Regarding the aforementioned challenges, ongoing multiangular observations are of prime interest. Maximum temperatures were captured in nadir and solar directions [58, 73, 108, 109]. Solar peak corresponds to the hot spot effect, with more sunlit surfaces in the solar direction. Nadir peak corresponds to a larger fraction of hot soil with a cooler vegetation. These measurements at the ground level have to be used along with modeling tools, for designing observation configurations and inversion methods.

\subsection{Forefront Investigations: Pertinently Using TIR Remote Sensing}

This section extends the discussion to its scientific context, with the use of land surface temperature for monitoring exchanges of heat, water and mass between soil, vegetation and atmosphere. For instance, the difficulties faced with aerodynamic temperature can be overcome using space or time differencing energy balance models. New difficulties are related to time and space issues. First, monitoring land surface processes from TIR remote sensing requires accounting for the fluctuating nature of surface temperature. Second, current spaceborne spatial resolutions do not systematically provide the appropriate scales for process modeling. This yields developing new approaches such as remote sensing data assimilation and aggregation / desegregation procedures.

Regarding the insufficient accuracy on surface temperature and the difficult use of aerodynamic temperature (Sections 10.6.2 and 10.6.3), several studies have suggested using soil and vegetation temperatures with two source models (Section 10.6.4). However, one source modeling with ensemble radiometric temperature 
still is very pertinent: time and space differencing models have been developed this last decade, to minimize errors on surface temperature. Spatially, is it possible adjusting air temperature from surface one, to make the gradient between both consistent [239]. Similarly, evaporative fraction can be derived from the radiometric temperature dynamic given an albedo range [59]. Temporally, surface fluxes can be estimated regarding the potentially extreme situations for the considered surfaces [22]. Similarly, time differencing between morning geostationary observations minimizes error on surface temperature [19]. These approaches have been widely validated for various environmental conditions, showing the pertinence of such differencing concepts $[19,22,23,25,60,66,240]$. However, they are limited by the agreement between the assumed and captured variabilities.

Monitoring land surfaces is performed using dynamic models which simulate the considered processes, such as the functioning of cultivated and natural vegetation [241, 242]. Assimilating remotely sensed information allows constraining model trajectory, to obtain consistent series for the considered processes and related variables. Model parameters and initial variables (respectively state variables) are adjusted (respectively readjusted) to make simulations and observations agreeing over a temporal window (respectively at a given time) [39, 243]. Minimizing differences between simulations and observations relies on stochastic methods and adjoint models [38, 244]. Solar and radar information can be directly assimilated, since the considered variables are almost temporally stable [242, 245-248]. Assimilating TIR observations requires adding a SVAT model, due to surface temperature fluctuations [29, 38, 39, 67, 137]. Then, the SVAT model document a simple radiative transfer equation for simulating surface brightness temperature (Section 10.6.1). To avoid using complex SVAT models, secondary variables such as energy fluxes or soil moisture can be assimilated in place of primary variables such as surface temperature [34, 249, 250].

Monitoring land surfaces from remote sensing faces the inadequation between process scales and spatial resolutions (Section 10.3.1). TIR remote sensors perform at hectometric resolutions with poor temporal samplings, or at kilometric resolutions with daily revisiting. Then, high spatial resolution observations provide valuable information for understanding heterogeneity effects and aggregation processes $[21,63,119,251-260]$. This is of interest for hydrology and meteorology, when the considered processes can be monitored at a kilometric resolution. Agricultural issues require higher spatial resolutions, in accordance with the field scale. Since TIR hectometric resolution remote sensors do not provide sufficient temporal sampling, a solution is desegregating daily kilometric resolution variables [261]. By using the well known vegetation index / temperature triangle, it is possible to desegregate TIR observations from solar ones, since the latter always have higher resolutions [56]. However, this is limited by soil moisture conditions [41, 258]. Other possibilities are statistical or deterministic desegregation. Statistical procedures have been applied at the landscape unit scale for solar observations [262]. Deterministic procedures have been proposed for TIR geostationary observations [115, 263]. 


\subsection{Concluding Remarks}

Significant progresses were achieved for the retrieval of ensemble emissivity and radiometric temperature, with accuracies almost close to requirements for many applications. Current efforts are refinements rather than new concepts. Regarding the difficult use of aerodynamic temperature, it is recommended focusing on soil and vegetation temperatures which are functionally equivalent. Then, the next challenge is deriving soil and vegetation temperatures with optional sunlit and shaded components, and canopy temperature profile from the soil to the top of canopy via vegetation layers.

Soil and vegetation temperatures can be recovered parameterizing and inverting simple radiative transfer equations, which simplicity is attractive for operational applications. More elaborated temperatures require finer approáches, with efforts to be made on measuring and modeling. Ground based goniometric systems allow capturing complex angular dynamics of brightness temperature. Simulation models currently under improvement are increasingly accurate. The next step is developing inversion methods such as inductive learning and lookup tables, already implemented over the solar domain. Expected difficulties result from the temperature profile which is driven by micro meteorological conditions. Given surface temperature fluctuations require along track observations from space, recovering temperature profile seems limited to few layers, optionally sunlit and shaded. This should allow designing optimal viewing configurations for spaceborne sensors, in terms of observation number and angular distribution.

Finally, current focuses on spatial and temporal issues are of importance. TIR spaceborne sensors do not provide optimum temporal monitoring and spatial scales. Adequate spatial resolutions and revisit rates still do not exist, despite the numerous missions proposed the last decade. While waiting for such information, it is necessary developing aggregation and desegregation methods, to benefit of spatial scales from high resolution sensors and daily monitoring from kilometric resolution sensors.

Acknowledgements This review article was possible thanks to numerous interactions, discussions and scientific exchanges, in the framework of various collaborations supported by several programs: the US ASTER Project of NASA's EOS-Terra Program (P.I. Thomas Schmugge), the US NASA EOS Grant 03-EOS-02 (P.I. Andrew French), the French PNTS program (project P.Is. Frederic Jacob and Albert Olioso), the French PNBC program (project P.I. Jean Claude Menaut), the French Inter Region MIP / PACA program (project P.I. Dominique Courault), and finally the program from the Department of Research, Development, and International Relations of Purpan Graduate School of Agriculture. Many thanks to the ISPMSRS 2005 sponsors for permitting this symposium. 


\section{References}

[1] Romanov P, Tarpley D (1993) Automated monitoring of snow cover over South America using GOES imager data. Int. J. Remote Sens. 24(5):11191125

[2] Kay J, Gillespie A, Hansen G, Pettit E (2003) Spatial relationships between snow contaminant content, grain size, and surface temperature from multispectral images of Mt. Rainier, Washington, DC (USA). Remote Sens. Environ. 86(2):216-231

[3] Aires F, Chédin A, Scott N, Rossow W. (2002) A regularized neural net approach for retrieval of atmospheric and surface temperatures with the IASI instrument. J. Appl. Meteorol. $41: 144-159$

[4] Aires F, Rossow W, Chédin A, Scott N (2002) Remote sensing from the infrared atmospheric sounding interferometer instrument 2. Simultaneous retrieval of temperature, water vapor, and ozone atmospheric profiles. J. Geophys. Res. 107(D22):4620

[5] Prigent C, Aires F, Rossow W (2003) Land surface skin temperatures from a combined analysis of microwave and infrared satellite observations for an all weather evaluation of the differences between air and skin temperatures. J. Geophys. Res. 108(D10):4310

[6] Hong G, Heygster G, Kunzi K (2005) Intercomparison of deep convective cloud fractions from passive infrared and microwave radiance measurements. IEEE Geosci. Remote Sens. Lett. 2(1):18-24

[7] Sunlner M, Michael K, Bradshaw C Hindell M (2003) Remote sensing of Southern Ocean sea surface temperature: implications for marine biophysical models. Remote Sens. Environ. 84(2):161-173

[8] Gould R, Arnone R (2004) Temporal and spatial variability of satellite sea surface temperature and ocean colour in the Japan/East Sea. Int. J. Remote Sens. 25(7-8):1377-1382

[9] Simpson J, Yueh L, Schmidt A, Harris A (2005) Analysis of along track scanning radiometer-2 (ATSR-2) data for clouds, glint and sea surface temperature using neural networks. Remote Sens. Environ. 152-181:161-183

[10] Quattrochi D, Luvall J (2003) Thermal remote sensing in land surface processes. Taylor \& Francis, London

[11] Justice CO, Giglio L, Korontzi S, Owens J, Morisette JT, Roy D, Descloitres J, Alleaume S, Petitcolin F, Kaufman Y (2002) The MODIS fire products. Remote Sens. Environ. 83:244-262

[12] Petitcolin F, Vermote E (2002) Land surface reflectance, emissivity and temperature from MODIS middle and thermal infrared data. Remote Sens. Environ. 83:112-134

[13] Kasischke ES, Hewson JH, Stocks B, van der Werf G, Randerson J (2003) The use of ATSR active fire counts for estimating relative patterns of biomass burning a study from the boreal forest region. Geophys. Res. Lett. 30(18):1969, doi:10.1029/2003GL017859 
[14] Manso-Delgado L, Aguirre-Gomez R, Alvarez R (2003) Multitemporal analysis of land surface temperature using NOAA-AVHRR: preliminary relationships between climatic anomalies and forest fires. Int. J. Remote Sens. 20:4417-4423

[15] Lo C, Quattrochi D, Luvall J (1997) Application of high-resolution thermal infrared remote sensing and GIS to assess the urban heat island effect. Int. J. Remote Sens. 18(2):287-304

[16] Lagouarde JP, Moreau P, Irvine M, Bonnefond JM, Voogt JA, Solliec F (2004) Airborne experimental measurements of the angular variations in surface temperature over urban areas: case study of Marseille (France). Remote Sens. Environ. 93:443-462

[17] Mestayer PG, Durand P, Augustin P, Basting S, Bonnefond JM, Benech B, Camp-istron B, Coppalle A, Delbarre H, Dousset B, Drobinski P, Druilhet A, Frejafon E, Grimmond, CSB, Groleau D, Irvine M, Kergomard C, Kermadi S, Lagouarde JP, Lemonsu A, Lohou F, Long N, Masson V, Moppert C, Noilhan J, Offerle B, Oke TR, Pigeon G, Puygrenier V, Roberts S, Rosant JM, Saïd F, Salmond J, Tal-baut M, Voogt J (2005) The urban boundary-layer field campaign in Marseille (UBL/CLU-escompte): set-up and first results. Boundary-Layer Meteorol. 114(2):315-365

[18] Olioso A, Taconet O, Ben Mehrez M (1996) Estimation of heat and mass fluxes from IR brightness temperature. IEEE Trans. Geosci. Remote Sens. 34:1184-1190

[19] Norman J, Kustas W, Prueger J, Diak GR (2000) Surface flux estimation using radiometric temperature: a dual-temperature-difference method to minimize measurement errors. Water Res. Res. 36:2263-2274

[20] Chehbouni A, Nouvellon Y, Lhomme J, Watts C, Boulet G, Kerr Y, Moran M, Goodrich D (2001) Estimation of surface sensible heat flux using dual angle observations of radiative surface temperature. Agric. Forest Meteorol. 108:55-65

[21] Wassenaar T, Olioso A, Hasager C, Jacob F, Chehbouni A (2002) Estimation of evapotran-spiration over heterogeneous pixels. In: Sobrino J (ed.) Proceedings of the First International Symposium on Recent Advances in Quantitative Remote Sensing, September 2002, Valencia, Spain, pp 458-465

[22] Su Z (2002) The Surface Energy Balance System (SEBS) for estimation of turbulent heat fluxes. Hydrol. Earth Sci. Syst. 6:85-99

[23] Jacob F, Olioso A, Gu X, Su Z, Seguin B (2002) Mapping surface fluxes using visible, near infrared, thermal infrared remote sensing data with a spatialized surface energy balance model. Agronomie: Agric. Environ. 22:669-680

[24] French A, Jacob F, Anderson M, Kustas W, Timmermans W, Gieske A, Su B, Su H, McCabe M, Li F, Prueger J, Brunsell N (2005) Surface energy fluxes with the Advanced Spaceborne Thermal Emission and Reflection radiometer (ASTER) at the Iowa 2002 SMACEX site (USA). Remote Sens. Environ. :55-65

[25] Courault D, Lacarrère P, Clastre P, Lecharpentier P, Jacob F, Marloie O, Prévot L, Olioso A (2003) Estimation of surface fluxes in a small agricultural 
area using the three-dimensional atmospheric model Meso-NH and remote sensing data. Can. J. Remote Sens. 29:741-754

[26] Olioso A, Carlson T, Brisson N (1996) Simulation of diurnal transpiration and photo-synthesis of a water stresses soybean crop. Agric. Forest Meteorol. 81:41-59

[27] Moran M, Vidal A, Troufleau D, Qi J, Clarke T Jr., Pinter PJ, Mitchell T, Inoue Y, Nealeg MU (1997) Combining Multifrequency Microwave and Optical Data for Crop Management. Remote Sens. Environ. 61:96-109

[28] Moran M, Inoue Y, Barnes E (1997) Opportunities and Limitations for ImageBased Remote Sensing in Precision Crop Management. Remote Sens. Environ. 61:319-346

[29] Cayrol P, Kergoat L, Moulin S, Dedieu G, Chehbouni A. (2000) Calibrating a coupled SVAT - vegetation growth model with remotely sensed reflectance and surface temperature. J. Appl. Meteorol. 39:2452-2472

[30] Bastiaanssen W, Molden D, Makin I (2000) Remote sensing for irrigated agriculture: examples from research and possible applications. Agric. Water Manag. 46:137-155

[31] Droogers P, Bastiaanssen W (2002) Irrigation performance using hydrological and remote sensing modeling. J. Irrig. Drain. Eng. 128:11-18

[32] Hale R, Duchon C (2003) Use of AVHRR-derived surface temperatures in evaluating a land-atmosphere model. Int. J. Remote Sens. 244527-4541

[33] Jacobs A, Ronda R, Holtslag A (2003) Water vapour and carbon dioxide fluxes over bog vegetation. Agric. Forest Meteorol. 116:103-112

[34] Schuurmans J, Troch P, Veldhuizen A, Bastiaanssen W, Bierkens M (2003) Assimilation of remotely sensed latent heat flux in a distributed hydrological model. Adv. Water Res. 26:151-159

[35] Nijbroek R, HoogenBoom G, Jones J (2003) Optimizing irrigation management for a spatially variable soybean field. Agric. Syst. 76:359-377

[36] Panda R, Behera S, Kashyap P (2003) Effective management of irrigation water for wheat under stress conditions. Agric. Water Manag. 6337-56

[37] Bastiaanssen W, Chandrapala L (2003) Water balance variability across Sri Lanka for assessing agricultural and environmental water use. Agric. Water Manag. 58:171-192

[38] Demarty J, Ottlé C, Braud I, Olioso A, Frangi JP, Gupta H, Bastidas L (2005) Constraining a physically based Soil-Vegetation-Atmosphere Transfer model with surface water content and thermal infrared brightness temperature measurements using a multiobjective approach. Water Resour. Res. 41 (2005) W01011, doi:10.1029/2004WR003695

[39] Olioso A, Inoue Y, Ortega-Farias S, Demarty J, Wigneron JP, Braud I, Jacob F, Lecharpentier P, Ottlé C, Calvet JC, Brisson N (2005) Future directions for advanced evap-otranspiration modeling: Assimilation of remote sensing data into crop simulation models and SVAT models. Irrig. Drain. Syst. 19(3-4):355-376 
[40] Capehart W, Carlson T (1997) Decoupling of surface and near-surface soil water content: A remote sensing perspective. Water Resour. Res. 33:13831395

[41] Gillies R, Carlson T, Cui J, Kustas W, Humes K (1997) Verification of the 'triangle' method for obtaining surface soil water content and energy fluxes from remote measurements of the Normalized Vegetation Index NDVI and surface radiant temperature. Int. J. Remote Sens. 18:3145-3166

[42] Inoue Y, Olioso A, Choi W (2004) Dynamic change of $\mathrm{CO}_{2}$ flux over bare soil field and its relationship with remotely sensed surface temperature. Int. J. Remote Sens. 25(10):1881-1892

[43] Coudert B, Ottlé C, Boudevillain B, Demarty J, Guillevic P (2005) Contribution of thermal infrared remote sensing data in multiobjective calibration of a dual source SVAT model. J. hydrometeorol (submitted).

[44] Sobrino J, Raissouni N (2000) Toward remote sensing methods for land cover dynamic monitoring. Application to Morroco. Int. J. Remote Sens. 21:353366

[45] Wilber A, Kratz D, Gupta S (1999) Surface emissivity maps for use in satellite retrievals of longwave radiation. NASA/TP-1999-209362, NASA

[46] Zhou L, Dickinson R, Ogawa K, Tian Y, Jin M, Schmugge T (2003) Relations between albedos and emissivities from MODIS and ASTER data over North African Desert. Geophys. Res. Lett. 30(20):2026, doi:10.1029/2003GL018069

[47] Zhou L, Dickinson R, Tian Y, Jin M, Ogawa K, Yu H, Schmugge T (2003) A sensitivity study of climate and energy balance simulations with use of satellite derived emissivity data over Northern Africa and the Arabian Peninsula. J. Geophys. Res. 108(D24):4795, doi:10.1029/2003JD004083

[48] Jin M, Liang S (2006) Improving Land surface emissivity parameter of land surface model in GCM. J. Climate 19:2867-2881

[49] Wan Z, Wang P, Li X (2004) Using MODIS Land Surface Temperature and Normalized Difference Vegetation Index products for monitoring drought in the southern Great Plains, USA. Int. J. Remote Sens. 25(1):61-72

[50] Norman J, Becker F (1995) Terminology in thermal infrared remote sensing of natural surfaces. Remote Sens. Rev. 12:159-173

[51] Dash P, Göttsche FM, Olesen FS, Fischer H (2002) Land surface temperature and emissivity estimation from passive sensor data: theory and practicecurrent trends. Int. J. Remote Sens. 23(13):2563-2594

[52] Ogawa K, Schmugge T, Jacob F, French A (2003) Estimation of land surface window $(8-12 \mu \mathrm{m})$ emissivity from multi-spectral thermal infrared remote sensing - a case study in a part of Sahara Desert. Geophys. Res. Lett. 30:1067-1071

[53] Ogawa K, Schmugge T (2004) Mapping Surface Broadband Emissivity of the Sahara Desert Using ASTER and MODIS Data. Earth Interactions 8 Paper No. 7

[54] Wang K, Wan Z, Wang P, Sparrow M, Liu J, Zhou X, Haginoya S (2005) Estimation of Surface Long Wave Radiation and Broadband Emissivity 
Using Moderate Resolution Imaging Spectroradiometer (MODIS) Land Surface Temperature/Emissivity Products. J. Geophys. Res. -Atmos. 110(D11, D11109) Paper No. 10.1029/2004JD005566

[55] Becker F, Li Z (1995) Surface temperature and emissivity at various scale: definition, measurement and related problem. Remote Sens. Reviews 12 225253

[56] Kustas W, Norman J, Anderson M, French A (2003) Estimating subpixel surface temperatures and energy fluxes from the vegetation index-radiometric temperature relationship. Remote Sens. Environ. 85429-440

[57] Nishida K, Nemani RR, Glassy JM, Running SW (2003) Development of an Evapotranspiration Index From Aqua/MODIS for Monitoring Surface Moisture Status. IEEE Trans. Geosci. Remote Sens. 41(2)

[58] Luquet D, Bégué A, Vidal A, Clouvel P, Dauzat J, Olioso A, Gu X, Yu T (2003) Using multidirectional thermography to characterize water status of cotton. Remote Sens. Environ. 84:411421

[59] Roerink GJ, Su Z, Menenti M (2000) S-SEBI: a simple remote sensing algorithm to estimate the surface energy balance. Phys. Chem. Earth (B) 25(2):147-157

[60] Gomez M, Sobrino J, Olioso A, Jacob F (2005) Retrieval of evapotranspiration over the Alpilles test site using PolDER and thermal camera data. Remote Sens. Environ. 96:399-408

[61] Kustas W, Humes K, Norman J, Moran M (1996) Single and dual source modeling of surface energy fluxes with radiometric surface temperature. J. Appl. Meteorol. 35110-121

[62] Chehbouni A, Lo Seen D, Njoku E, Monteny B (1996) Examination of the difference between radiative and aerodynamic surface temperatures over sparsely vegetated surfaces. Remote Sens. Environ. 58177186

[63] Chehbouni A, Lo Seen D, Njoku E, Lhomme JP, Monteny B, Kerr Y (1997) Estimation of sensible heat flux over sparsely vegetated surfaces. J. Hydrol. 188189:855868

[64] Habets F, Noilhan J, Golaz C, Goutorbe JP, Lacarrère P, Leblois E, Ledoux E, Martin E, Ottlé C, Vidal-Madjar D (1999) The ISBA surface scheme in a macroscale hydro-logical model applied to the Hapex-Mobilhy area. Part I: model and database. J. hydrol. 21775-96

[65] Su Z, Menenti M, Pelgrum H, van den Hurk B, Bastiaanssen W (1999) Remote sensing of land surface fluxes for updating numerical weather predictions. In: Nieuwenhuis, Vaughan, Molenaar (eds), Operational Remote Sensing for Sustainable Development, Balkema, Rotterdam

[66] Li J, Su Z, van den Hurk B, Menenti M, Moene A, de Bruin H, Baselga Yrisarry J, Ibanez M, Cuesta A. (2003) Estimation of sensible heat flux using the Surface Energy Balance System (SEBS) and ATSR measurements. Phys. Chem. Earth 28:75-88

[67] Demarty J, Ottlé C, Braud I, Olioso A, Frangi JP, Bastidas L, Gupta H (2004) Using a multiobjective approach to retrieve information on surface properties used in a SVAT model. J. Hydrol. 287:214-236 
[68] François C (2002) The potential of directional radiometric temperatures for monitoring soil and leaf temperature and soil moisture status. Remote Sens. Environ. 80122-133

[69] Braud I, Dantas Antonino A, Vauclin M, Thony J, Ruelle P (1995) A Simple Soil Plant Atmosphere Transfer model (SiSPAT) development and field verification. J. Hydrol. 166:213-250

[70] Boulet G, Chehbouni A, Braud I, Vauclin M (1999) Mosaic versus dual source approaches for modeling the surface energy balance of a semi-arid land. Hydrol. Earth Sci. Syst. 3(2):247-258

[71] Merlin O, Chehbouni A (2004) Different approaches in estimating heat flux using dual angle observations of radiative surface temperature. Int. J. Remote Sens. 25:275-289

[72] Luquet D, Vidal A, Dauzat J, Bégué A, Olioso A, Clouvel P (2003) Using directional TIR measurements and 3D simulations to assess the limitations and opportunities of water stress indices. Remote Sens. Environ. 9053-62

[73] Yu T, Gu X, Tian T, Legrand M, Baret F, Hanocq JF, Bosseno R, Zhang Y (2004) Modeling directional brightness temperature over a maize canopy in row structure. IEEE Trans. Geosci. Remote Sens. 42:2290-2304

[74] Verhoef W, Xiao Q, Jia L, Su Z (2006) Earth observation modeling based on layer scattering matrices. IEEE Trans. Geosci. Remote Sens. (submitted).

[75] Smith J Jr, Ballard, J.R (1999) Physics Based Modeling and Rendering of Vegetation in the Thermal Infrared. In: 1999 IEEE Workshop on Photometric Modeling for Computer Vision and Graphics 34

[76] Guillevic P, Gastellu-Etchegorry JP, Demarty J, Prévot L (2003) Thermal infrared radiative transfer within three-dimensional vegetation cover. J. Geophys. Res. -Atm. 108(D8):4248, doi:10.1029/2002JD02247

[77] Gastellu-Etchegorry JP, Martin E, Gascon F (2004) DART: a 3D model for simulating satellite images and studying surface radiation budget. Int. J. Remote Sens. 25(1):73-96

[78] Belot A, Gastellu-Etchegorry JP, Perrier A (2005) DART-EB, a 3-D model of mass and energy transfers in vegetated canopy. Remote Sens. Environ. (submitted)

[79] Seguin B, Becker F, Phulpin T, Gu X, Guyot G, Kerr Y, King C, Lagouarde J, Ottlé C, Stoll M, Tabbagh T, Vidal A (1999) IRSUTE: a minisatellite project for land surface heat flux estimation from field to regional scale. Remote Sens. Environ. 68:357-369

[80] Hernandez-Baquero ED (2000) Characterization of the Earth's Surface and Atmosphere from Multispectral and Hyperspectral Thermal Imagery. Ph.D. thesis, Air Force Institute of Technology, Wright-Patterson, AFB, OH, 270pp.

[81] French A, Norman J, Anderson M (2003) A simple and fast atmospheric correction for space-borne remote sensing of surface temperature. Remote Sens. Environ. 87:326-333

[82] Sobrino J, Romaguera M (2004) Land surface temperature retrieval from MSG1-SEVIRI data. Remote Sens. Environ. 92 247-254 
[83] Petitcolin F, Nerry F, Stoll MP (2002) Mapping temperature independent spectral indice of emissivity and directional emissivity in AVHRR channels 4 and 5. Int. J. Remote Sens. 23:3473-3491

[84] Nakajima T, Nakajima T, Nakajima M, Fukushima H, Kuji M, Uchiyama A, Kishino M (1998) Optimization of the Advanced Earth Observing Satellite (ADEOS) II Global Imager (GLI) channels by use of radiative transfer calculations. Appl. Opt. 37(15):3149-3163

[85] Justice C, Vermote E, Townshend J, Defries R, Roy D, Hall D, Salomonson V, Privette J, Riggs G, Strahler A, Lucht W, Myneni R, Knyazikhin Y, Running S, Ne-mani R, Wan Z, Huete A, van Leeuwen W, Wolfe R, Giglio L, Muller JP, Lewis P, Barnsley M (1998) The MODerate Imaging Spectroradiometer (MODIS): land remote sensing for global change research. IEEE Trans. Geosci. Remote Sens. 36:1228-1249

[86] Llewellyn-Jones D, Edwards M, Mutlow C, Birks A, Barton I, Tait H (2001) AATSR: global-change and surface-temperature measurements from Envisat. Eur Space Agency Bull 105:11-21

[87] Goward S, Masek J, Williams D, Irons J, Thompson R (2001) The Landsat 7 mission - Terrestrial research and applications for the 21 st century. Remote Sens. Environ. 78:3-12

[88] Yamaguchi Y, Kahle A, Tsu H, Kawakami T, Pniel M (1998) Overview of Advanced Space-borne Thermal Emission and Reflection Radiometer (ASTER). IEEE Trans. Geosci. Remote Sens. 36:1282-1289

[89] Becker F, Seguin B, Phulpin T, Durpaire J (1996) IRSUTE, a small satellite for water budget estimate with high resolution infrared imagery. Acta Astronautica 39:883-897

[90] Lagouarde J (1997) SEXTET: a high resolution and high repetitivity infra red instrument on a mini satellite platform. Proposal to CNES call for ideas

[91] Menenti M, Rast M, Baret F, van den Hurk B, Knorr W, Mauser W, Miller J, Moreno J, Schaepman M, Verstraete M.M (2004) Understanding vegetation response to climate variability from space: recent advances towards the SPECTRA Mission. In: Meynart R (ed) Proceedings of SPIE: Sensors, Systems, and Next-Generation Satellites VII. Vol 5234, pp 76-85

[92] Weber PG, Brock BC, Garrett AJ, Smith BW, Borel CC, Clodius WB Bender SC, Kay RR, Decker ML (1999) MTI Mission Overview. In: Proceedings of SPIE Conference on Imaging Spectrometry V. Vol 3753, pp 340-346

[93] Palluconi F, Meeks G (1985) Thermal Infrared Multi-spectral Scanner (TIMS): an investigator's guide to TIMS data. JPL Publications, pp 85-32

[94] Müller A, Gege P, Cocks T (2001) The airborne imaging spectrometers used in daisex. In: DAISEX Final Results Workshop, ESTEC, Holland, 15-16 March 2001, ESA SP-499, pp 3-6

[95] King MD, Menzel WP, Grant PS, Myers JS, Arnold GT, Platnick SE, Gumley LE, Tsay SC, Moeller CC, Fitzgerald M, Brown KS, Osterwisch FG (1996) Airborne scanning spectrometer for remote sensing of cloud, aerosol, water vapor and surface properties. J. Atm. Oceanic Technol. 13:777-794 
[96] Hook S, Myers J, Thome K, Fitzgerald M, Kahle A (2001) The MODIS/ ASTER airborne simulator (MASTER) - a new instrument for Earth science studies. Remote Sens. Environ. 76:93-102

[97] Prévot L, Baret F, Chanzy A, Olioso A, Wigneron J, Autret H, Baudin F, Besse-moulin P, Bethenod O, Blamont D, Blavoux B, Bonnefond J, Boubkraoui S, Bouman B, Braud I, Bruguier N, Calvet J, Caselles V, Chauki H, Clevers J, Coll C, Company A, Courault D, Dedieu G, Degenne P, Delécolle R, Denis H, Desprats J, Ducros Y, Dyer D, Fies J, Fischer A, Francois C, Gaudu J, Gonzalez E, Gouget R, Gu X, Guérif M, Hanocq J, Hautecoeur J, Haverkamp R, Hobbs S, Jacob F, Jeansoulin R, Jongschaap R, Kerr Y, King C, Laborie P, Lagouarde J, Laques A, Larcena D, Laurent G, Laurent J, Leroy M, McAneney J, Macelloni G, Moulin S, Noilhan J, Ottlé C, Paloscia S, Pampaloni P, Podvin T, Quaracino F, Roujean J, Rozier C, Ruisi R, Susini C, Taconet O, Tallet N, Thony J, Travi Y, Van Leewen H, Vauclin M, Vidal-Madjar D, Vonder O, Weiss M (1998) Assimilation of multi-sensor and multi-temporal remote sensing data to monitor vegetation and soil: the Alpilles ReSeDA project. In: Tsang L (ed) IGARSS '98 International Geoscience and Remote Sensing Symposium, IEEE, Institute of Electrical and Electronics Engineers, Piscataway (USA), Sensing and managing the environment. Vol 5, pp 2399-2401

[98] Olioso A, Prévot L, Baret F, Chanzy A, Braud I, Autret H, Baudin F, Bessemoulin P, Bethenod O, Blamont D, Blavoux B, Bonnefond J, Boubkraoui S, Bouman B, Bruguier N, Calvet J, Caselles V, Chauki H, Clevers J, Coll C, Company A, Courault D, Dedieu G, Degenne P, Delécolle R, Denis H, Desprats J, Ducros Y, Dyer D, Fies J, Fischer A, Francois C, Gaudu J, Gonzalez E, Gouget R, Gu X, Guérif M, Hanocq J, Hautecoeur J, Haverkamp R, Hobbs S, Jacob F, Jeansoulin R, Jongschaap R, Kerr Y, King C, Laborie P, Lagouarde J, Laques A, Larcena D, Laurent G, Laurent J, Leroy M, McAneney J, Macelloni G, Moulin S, Noilhan J, Ottlé C, Paloscia S, Pampaloni P, Podvin T, Quaracino F, Roujean J, Rozier C, Ruisi R, Susini C, Taconet O, Tallet N, Thony J, Travi Y, Van Leewen H, Vauclin M, Vidal-Madjar D, Vonder O, Weiss M, Wigneron J (1998) Spatial aspects in the Alpilles-ReSeDA project. In: Marceau D (ed.) Scaling and Modeling in Forestry: Application in Remote Sensing and GIS, Ed. D Marceau, Université de Montréal, Québec pp 92-102

[99] Baret F (2000) ReSeDA, assimilation of multisensor and multitemporal remote sensing data to monitor soil and vegetation functioning. Final Report EC project ENV4CT960326, INRA, France, 59p.

[100] National Research Council (2004) Committee on NASA-NOAA Transition from Research to Operations: Satellite Observations of the Earth's Environment: Accelerating the Transition of Research to Operations. National Academies Press, Washington, DC

[101] Yu Y, Privette J, Pinheiro A (2005) Analysis of the NPOESS VIIRS Land Surface Temperature Algorithm Using MODIS Data. IEEE Trans. Geosci. Remote Sens. 43:2340-2350 
[102] Vaughan R, Calvin W, Taranik J (2003) SEBASS hyperspectral thermal infrared data: surface emissivity measurement and mineral mapping. Remote Sens. Environ. 85:48-63

[103] Liu Q, Gu X, Li X, Jacob F, Hanocq JF (2000) Study on airborne experiment for directional patterns of thermal infrared radiation. Science in China(E) 30:89-97

[104] Payan V, Royer A (2004) Analysis of the Temperature Emissivity Separation (TES) algorithm applicability and sensitivity. Int. J. Remote Sens. 25:15-37

[105] Rubio E, Caselles V, Badenas C (1997) Emissivity measurements of several soils and vegetation types in the $8-14 \mu \mathrm{m}$ wave band: analysis of two fields method. Remote Sens. Environ. 59:490-521

[106] Kant Y, Badarinath K (2002) Ground-based method for measuring thermal infrared effective emissivity and perspectives on the measurement of land surface temperature from satellite data. Int. J. Remote Sens. 23(11):21792191

[107] Rubio E, Caselles V, Coll C, Valor E, Sospedra F (2003) Thermal infrared emissivities of natural surfaces: improvement on the experimental set-up and new measurements. Int. J. Remote Sens. 24(24):5379-5390

[108] Li ZL, Zhang R, Sun X, Su H, Tang X, Zhu Z, Sobrino JA (2004) Experimental system for the study of the directional thermal emission of natural surfaces. Int. J. Remote Sens. 25(1):195-204

[109] Coret L, Briottet X, Kerr Y, Chehbouni G (1973) Experimental study of directional aggregation over heterogeneous surfaces in the thermal infrared. Remote Sens. Environ. (submitted).

[110] Garrat J, Hicks B (1973) Momentum, heat and water vapor transfer to and from natural and artificial surfaces. Quart. J. Roy. Meteorol. Soc. 99:680687

[111] Ham J, Heilman J (1991) Aerodynamic land surface resistances affecting energy transport in a sparse crop. Agric. Forest Meteorol. 53:267-284

[112] Garrat J (1978) Transfer characteristics for a heterogeneous surface of large aerodynamic roughness. Quart. J. Roy. Meteorol. Soc. 104:491-502

[113] Troufleau D, Lhomme J, Monteny B, Vidal A (1997) Sensible heat flux and radiometric surface temperature over sparse Sahelian vegetation. I. An Experimental analysis of the kB parameter. J. Hydrol. 188-189:815-838

[114] Choudhury B (1989) Estimating evaporation and carbon assimilation using infrared temperature data: vistas in modeling. In: Theory and Applications of Optical Remote Sensing. Wiley Interscience, Paris, France, pp 629-690

[115] Norman J, Divakarla M, Goel N (2000) Algorithms for Extracting Information from Remote Thermal-IR Observations of the Earth's Surface. Remote Sens. Environ. $51: 157-168$

[116] Martonchik JV, Bruegge CJ, Strahler AH (2000) A Review of Reflectance Nomenclature for Remote Sensing. Remote Sens. Rev. 19:9-20

[117] Li X, Strahler A, Friedl M (1999) A conceptual model for effective directional emissivity from non-isothermal surfaces. IEEE Trans. Geosci. Remote Sens. 37:2508-2517 
[118] François C, Ottlé C, Prévot L (1997) Analytical parameterization of canopy directional emis-sivity and directional radiance in the thermal infrared. Application on the retrieval of soil and foliage temperatures using two directional measurements. Int. J. Remote Sens. 18:2587-2621

[119] Chehbouni A, Nouvellon Y, Kerr Y, Moran M, Watts C, Prévot L, Goodrich D, Rambal S (2001) Directional effect on radiative surface temperature measurements over a semi-arid grassland site. Remote Sens. Environ. 76:360-372

[120] Olioso A (2006) Evidences of low land surface thermal infrared emissivity in presence of dry vegetation. IEEE Geosci. Remote Sens. Lett. (in press).

[121] Sutherland R, Bartholic J (1977) Significance of vegetation in interpreting thermal radiation from a terrestrial surface. J. Appl. Meteorol. 16:759-763

[122] Colton A (1996) Effective thermal parameters for a heterogeneous lans surface. Remote Sens. Environ. 57:143-160

[123] Barducci A, Pippi Y (1996) Temperature and emissivity retrieval from remotely sensed images using the "Grey Body Emissivity" method. IEEE Trans. Geosci. Remote Sens. 34:681-695

[124] Valor E, Caselles V (1996) Mapping land surface emissivity from NDVI: application to European, African and South American areas. Remote Sens. Environ. 57:167-184

[125] Sobrino J, Sòria G, Prata AJ (2004) Surface temperature retrieval from Along Track Scanning Radiometer 2 data: Algorithms and validation. J. Geophys. Res. 109D11101, doi:10.1029/2003JD004212

[126] Sòria G, Sobrino J (2006) Envisat/aatsr derived land surface temperature over a heterogeneous region. Remote Sens. Environ. (submitted).

[127] Chen L, Li ZL, Liu Q, Chen S, Tang Y, Zhong B (2004) Definition of component effective emissivity for heterogeneous and non-isothermal surfaces and its approximate calculation. Int. J Remote Sens. 25(1):231-244

[128] Su L, Li X, Friedl M, Strahler A, Gu X (2002) A kernel-driven model of effective directional emissivity for non-isothermal surfaces. Prog. Natural Sci. 12(8):603-607

[129] Snyder W, Wan Z (1998) BRDF models to predict spectral reflectance and emissivity in the infrared. IEEE Trans. Geosci. Remote Sens. 36:214-225

[130] Roujean J, Leroy M, Deschamps P (1992) A bidirectional reflectance model of the Earth's surface for the correction of remote sensing data. J. Geophys. Res. 97:20455-20468

[131] Wanner W, Li X, Strahler A (1995) On the derivation of kernels for kerneldriven models of bidirectional reflectance. J. Geophys. Res. 100:2107721089

[132] Engelsen O, Pinty B, Verstraete M, Martonchik J (1996) Parametric bidirectional reflectance factor models : evaluation, improvements and applications. Report EUR16426EN, European Commission, Joint Researches Center, Space Application Institute, ISPRA, Italy

[133] Berk A, Bernstein L, Anderson G, Acharya P, Robertson D, Chetwynd J, Adler-Golden S (1998) MODTRAN cloud and multiple scattering upgrades with application to AVIRIS. Remote Sens. Environ. 65:367-375 
[134] Anderson G, Berk A, Acharya P, Matthew M, Bernstein L, Chetwynd J, Dothe H, Adler-Golden S, Ratkowski A, Felde G, Gardner J, Hoke M, Richtsmeier S, Pukall B, Mello J, Jeong L (2000) MODTRAN 4.0: radiative transfer modeling for remote sensing. In: Algorithms for multispectral, hyperspectral and ultraspectral imagery VI: Proceedings of SPIE , pp 176183

[135] Verhoef, W. (1984) Light scattering by leaf layers with application to canopy reflectance modeling: the SAIL model. Remote Sens. Environ. 16:125-141

[136] Olioso A (1995) Simulating the relationship between thermal infrared emissivity and the Normalized Difference Vegetation Index. Int. J. Remote Sens. 16:3211-3216

[137] Olioso A, Chauki H, Courault D, Wigneron J (1999) Estimation of evapotranspiration and photo-synthesis by assimilation of remote sensing data into SVAT models. Remote Sens. Environ. 68:341-356

[138] Kimes D (1980) Effects of vegetation canopy structure on remotely sensed canopy temperatures. Remote Sens. Environ. 10:165-174

[139] Prévot L (1985) Modélisation des échanges radiatifs au sein des couverts végétaux - Application à la télédétection - Validation sur un couvert de Maïs. Ph.D. thesis, p 185, Université Paris VI, Paris, France

[140] Jackson R, Reginato R, Pinter P (1979) Plant canopy information extraction from composite site reflectance of row crop. Appl. Opt. 18:3775-3782

[141] Kimes D, Kirchner J (1983) Directional radiometric measurements of row crop temperatures. Int. J. Remote Sens. 4:299-311

[142] Sobrino JA, Caselles V (1990) Thermal infrared radiance model for interpreting the directional radiometric temperature of a vegetative surface. Remote Sens. Environ. 33:193-199

[143] Caselles V, Sobrino JA, Coll C (1992) A physical model for interpreting the land surface temperature obtained by remote sensors over incomplete canopies. Remote Sens. Environ. 39203-211

[144] Coret L, Briottet X, Kerr Y, Chehbouni G (2004) Simulation study of view angle effects on thermal infrared measurements over heterogeneous surfaces. IEEE Trans. Geosci. and Remote Sens. 42(3):664-672

[145] Du Y, Liu Q, Chen L, Liu Q, YU, T (2006) Modeling directional brightness temperature of the winter wheat canopy at the ear stage. IEEE Trans. Geosci. Remote Sens. (submitted).

[146] Norman J, Campbell G (1983) Application of a plant-environment model to problems in irrigation. In: Hillel D (ed.) Advances in irrigation, Academic Press, New York, pp 155-188

[147] Norman J, Arkebauer T (1991) Predicting canopy light-use efficiency from leaf characteristics. In: Ritchie J, Hanks R (eds), Modeling plant and soil systems, ASA, Madison, WI, pp 125-143

[148] Dauzat J, Rapidel B, Berger A (2001) Simulation of leaf transpiration and sap flow in virtual plants: description of the model and application to a coffee plantation in Costa Rica. Agric. Forest Meteorol. 109:143-160 
[149] Jia L (2004) Modeling heat exchanges at the land atmosphere interface using multi-angular thermal infrared measurements. Ph.D. thesis, Wageningen University, Wageningen, The Netherlands

[150] Su H, Zhang R, Tang XZ, Sun X (2000) Determination of the effective emissivity for the regular and irregular cavities using Monte-carlo method. Int. J. Remote Sens. 21(11):2313-2319

[151] Su L, Li X, Liang S, Strahler A (2003) Simulation of scaling effects of thermal emission from non-isothermal pixels with the typical three dimension structure. Int. J. Remote Sens. 24(19):3743-3753

[152] Kimes D, Knyazikhin Y, Privette J, Abuelgasim A, Gao F (2000) Inversion methods for physically-based models. Remote Sens. Rev. 18:381-439

[153] Chen J, Li X, Nilson T, Strahler A (2000) Recent advances in geometrical optical modeling and its applications. Remote Sens. Rev. 18:227-262

[154] Qin W, Liang S (2000) Plane-parallel canopy radiation transfer modeling: recent advances and future directions. Remote Sens. Rev. 18:281-305

[155] Nolin A, Liang S (2000) Progress in bidirectional reflectance modeling and applications for surface particulate media: snow and soils. Remote Sens. Rev. 18:307-342

[156] Lucht W, Roujean J (2000) Considerations in the parametric modeling of BRDF and albedo from multiangular satellite sensor observations. Remote Sens. Rev. 18343-379

[157] Schmugge T, French A, Ritchie J, Rango A, Pelgrum H (2002) Temperature and emissivity separation from multispectral thermal infrared observations. Remote Sens. Environ. 79:189-198

[158] Jacob F, Petitcolin F, Schmugge T, Vermote E, Ogawa K, French A (2004) Comparison of land surface emissivity and radiometric temperature from MODIS and ASTER sensors. Remote Sens. Environ. 83:1-18

[159] Hall F, Huemmrich K, Goetz S, Sellers P, Nickeson P (1992) Satellite remote sensing of surface energy balance : success, failures and unresolved issues in FIFE. J. Geophys. Res. 97:19061-19089

[160] Bolle H, et al. (1993) EFEDA: European Field in Desertification threatened Area. Annales Geophysicae 11:173-189

[161] Goutorbe J, et al. (1994) HAPEX-SAHEL: a large scale study of landatmosphere interactions in the semiarid tropics. Annales Geophysicae 12: 53-64

[162] Havstad K, Kustas W, Rango A, Ritchie J, Schmugge T (2000) Jornada Experimental Range: a unique arid land location for experiments to validate satellite system. Remote Sens. Environ. 74:13-25

[163] Baldocchi D, Falge E, Gu LH, Olson R, Hollinger D, Running S, Anthoni P, Bern-hofer C, Davis K, Evans R, Fuentes J, Goldstein A, Katul G, Law B, Lee XH, Malhi Y, Meyers T, Munger W, Oechel W, Paw UKT, Pilegaard K Schmid HP, Valentini R, Verma S (2001) FLUXNET: a new tool to study the temporal and spatial variability of ecosystem-scale carbon dioxide, water vapor, and energy flux densities. Bull. Am. Meteorol. Soc. 82-11:2415-2434 
[164] Berger M, Rast M, Wursteisen P, Attema E, Moreno J, Mueller A, Beisl U, Richter R, Schaepman M, Strub G, Stoll MP, Nerry F, Leroy M (2001) The DAISEX campaigns in support of a future land-surface-processes mission ESA Bulletin. Remote Sens. Environ. 105:101-111

[165] Goodrich DC, Chehbouni A, Goff BF, Macnish R, Maddock T, Moran MS, Shut-tleworth WJ, Williams DG, Watts CJ, Hipps LJ, Cooper DI, Schieldge J, Kerr YH, Arias H, Kirkland M, Carlos R, Cayrol P, Kepner W, Jones B, Avissar R, Begue A, Bonnefond JM, Boulet G, Branan B, Brunel JP, Chen LC, Clarke T, Davis MR, Debruin H, Dedieu G, Elguero E, Eichinger WE, Everitt J, Garatuza-Payan J, Gempko VL, Gupta H, Harlow C, Hartogensis O, Helfert M, Holifield C, Hymer D, Kahle A, Keefer T, Krishnamoorthy S, Lhomme JP, Lagouarde JP, Lo Seen D, Luquet D, Marsett R, Monteny B, Ni W, Nouvellon Y, Pinker R, Peters C, Pool D, Qi J, Rambal S, Rodriquez J, Santiago F, Sano E, Schaeffer SM, Schulte M, Scott R, Shao X, Snyder KA, Sorooshian S, Unkrich CL, Whitaker M, Yucel I (2000) Preface paper to the Semi-Arid Land-Surface- Atmosphere (SALSA) Program special issue. Agric. Forest Meteorol. 105:320

[166] Njoku E, Lakshmi V, O’Neill P (2004) Soil moisture field experiment special issue. Remote Sens. Environ. 92425-426

[167] Schmugge T, Hook S, Coll C (1998) Recovering surface temperature and emissivity from thermal infrared multispectral data. Remote Sens. Environ. 65:121-131

[168] Coll C, Caselles V, Rubio E, Sospedra F, Valor E (2000) Temperature and emissivity separation from calibrated data of the Digital Airborne Imaging Spectrometer. Remote Sens. Environ. 76250-259

[169] Buongiorno M, Realmuto V, Doumaz F (2002) Recovery of spectral emissivity from thermal infrared multispectral scanner imagery acquired over a mountainous terrain: a case study from mount Etna, Sicily. Remote Sens. Environ. 79:123-133

[170] Coll C, Caselles V, Rubio E, Valor E, Sospedra F, Baret F, Prévot L, Jacob F (2002) Temperature and emissivity extracted from airborne multi-channel data in the ReSeDA experiment. Agronomie: Agric. Environ. 22:567-574

[171] Jacob F, Gu X, Hanocq JF, Baret F (2003) Atmospheric corrections of single broadband channel and multidirectional airborne thermal infrared data. Application to the ReSeDA Experiment. Int. J. Remote Sens. 24:3269-3290

[172] Coll C, Caselles V, Valor E, Rubio E (2003) Validation of temperatureemissivity separation and split-window methods from TIMS data and ground measurements. Remote Sens. Environ. 85:232-242

[173] Coll C, Valor E, Caselles V, Niclòs R (2003) Adjusted Normalized Emissivity Method for surface temperature and emissivity retrieval from optical and thermal infrared remote sensing data. J. Geophys. Res. 108(D23):4739, doi:10.1029/2003JD003688

[174] Sobrino J, Jimenez-Munoz J, El-Kharraz J, Gomez M, Romaguera M, Sòria G (2004) Single-channel and two-channel methods for land surface temperature retrieval from DAIS data and its application to the Barrax site. Int. J. Remote Sens. 25(1):215-230 
[175] Schmugge T, Jacob F, A., F, Ogawa K (2002) Quantitative estimates of emissivity using ASTER data. In: Sobrino J (ed.) Proceedings of the First International Symposium on Recent Advances in Quantitative Remote Sensing, September 2002, Valencia, Spain , pp 585-589

[176] Schmugge T, Ogawa K, Jacob F, French A, Hsu Y, Ritchie J, Rango A (2003) Validation of emissivity estimates from ASTER data. In: Proceedings of 2003 International Geoscience and Remote Sensing Symposium, Toulouse, France, 21-25 July 2003. Vol III , pp 1873-1875

[177] Sobrino J, Jimenez-Munoz J, Paolini L (2004) Land surface temperature retrieval from Land-sat TM 5. Remote Sens. Environ. 90:434-440

[178] Li F, Jackson T, Kustas W, Schmugge T, French A, Cosh M, Bindlish R (2004) Deriving land surface temperature from Landsat 5 and 7 during SMEX02/SMACEX. Remote Sens. Environ. 92:521-534

[179] Jimenez-Munoz JC, Sobrino JA, Gillespie A, Sabol D, Gustafson TG (2006) Improved land surface emissivities over agricultural areas using ASTER NDVI. Remote Sens. Environ. 103:474-487

[180] Jimenez-Munoz JC, Sobrino JA (2003) A generalized single-channel method for retrieving land surface temperature from remote sensing data. J. Geophys. Res. 108(D22):4688, doi:10.1029/2003JD003480

[181] Wan Z, Zhang Y, Zhang Q, Li ZL (2002) Validation of the land surface temperature products retrieved from Terra Moderate Resolution Imaging Spectroradiometer data. Remote Sens. Environ. 83:163-180

[182] Wan Z, Zhang Y, Zhang Q, Li ZL (2004) Quality assessment and validation of the MODIS global land surface temperature. Int. J. Remote Sens. 25:261274

[183] Coll C, Caselles V, Galve JM, Valor E, Niclòs R, Sánchez J, Rivas R (2005) Ground measurements for the validation of land surface temperatures derived from AATSR and MODIS data. Remote Sens. Environ. 97:288-300

[184] Weiss M, Baret F, Garrigues S, Lacaze R (2006) Methods for the validation of land products derived from Medium Resolution sensors: application to CYCLOPES V3.0 and MODIS Coll. 4 LAI product. Remote Sens. Environ. (submitted).

[185] Tonooka H (2001) An atmospheric correction algorithm for thermal infrared multispectral data over land - a water vapor scaling method. IEEE Trans. Geosci. Remote Sens. 39:682-692

[186] Dash P, Göttsche FM, Olesen FS (2002) Potential of MSG for surface temperature and emissivity estimation: considerations for real-time applications. Int. J. Remote Sens. 23(20):4511-4518

[187] Peres L, DaCamara C (2004) Land surface temperature and emissivity estimation based on the two-temperature method: sensitivity analysis using simulated MSG/SEVIRI data. Remote Sens. Environ. 91:377-389

[188] Dash P, Göttsche FM, Olesen FS, Fischer H (2005) Separating surface emissivity and temperature using two-channel spectral indices and emissivity composites and comparison with a vegetation fraction method. Remote Sens. Environ. 961-17 
AQ: Please provide Author name.
[189] Jia L, Li Z, Menenti M, Su Z, Verhoef W, Wan Z (2003) A practical algorithm to infer soil and foliage component temperatures from bi-angular ATSR-2 data. Int. J. Remote Sens. 24:4739-4760

[190] Kratz DP, Chou MD, Michael M-H, YM., Ho, CH (1998) Minor Trace Gas Radiative Forcing Calculations Using the k Distribution Method with OneParameter Scaling. J. Geophys. Res. 103(D24):31647-31656

[191] Saunders R, Brunel P, English S, Bauer P, OKeeffe U, Francis P, Rayer P (2005) Rttov-8, science and validation report. Technical report, EUMESAT (2005) report NWPSAF-MO-TV-007, v1.2, 02/03/2005

[192] Gottsche FM, Olesen F (2002) Evolution of neural networks for radiative transfer calculations in the terrestrial infrared. Remote Sens. Environ. 80:157-164

[193] Derber J, Parrish D, Lord S (1991) The new global operational analysis system at the National Meteorological Center (NMC). Weather Forecast. 6:538547

[194] Derber J, Wu W (1998) The use of TOVS cloud-cleared radiances in the NCEP SSI analysis system. Monthly Weather Rev. 126:2287-2299

[195] Schroedter M, Olesen FS, Fischer H (2003) Determination of land surface temperature distributions from single channel IR measurements: an effective spatial interpolation method for the use of TOVS, ECMWF, and radiosonde profiles in the atmospheric correction scheme. Int. J. Remote Sens. 24:11891196

[196] Hirano A, Welch R, Lang H (2002) Mapping from ASTER stereo image data: DEM validation and accuracy assessment. ISPRS J. Photogramm. Remote Sens. 55:1-15

[197] Gu D., Gillespie AR, Kahle AB, Palluconi FD (2000) Autonomous atmospheric compensation (AAC) of high resolution hyperspectral thermal infrared remote sensing imagery. IEEE Trans. Geosci. Remote Sens. 38:2557-2569

[198] Li ZL, Li J, Su Z, Wan Z, Zhang R (2003) A new approach for retrieving precipitable water from ATSR2 split-window channel data over land area. Int. J. Remote Sens. 24(24):5095-5117

[199] Sobrino J, El Kharraz J, Li ZL (2003) Surface temperature and water vapor retrieval from MODIS data. Int. J. Remote Sens. 24(24):5161-5182

[200] De Felice T, LLoyd D, Meyer D, Baltzer T, Piraino P (2003) Water vapour correction of the daily $1 \mathrm{~km}$ AVHRR global land dataset: part I - validation and use of the water vapour input field. Int. J. Remote Sens. 24(11):23652375

[201] Rabier F, Fourrié N, Chafaï D, Prunet P (2001) Channel selection methods for infrared atmospheric sounding interferometer radiances. Quart. J. Roy. Meteorol. Soc. 128:1-17

[202] Pinheiro A, Privette J, Mahoney R, Tucker C (2004) Directional effects in a daily AVHRR land surface temperature dataset over Africa. IEEE Trans. Geosci. Remote Sens. 42(9):1941-1954 
[203] van de Griend A, Owe M (1993) On the relationship between thermal infrared emissivity and the Normalized Difference Vegetation Index for natural surfaces. Int. J. Remote Sens. 14 :1119-1131

[204] Kerr Y, Lagouarde J, Nerry F, Ottlé C (2004) Land surface temperature retrieval techniques and applications: case of the AVHRR. In: Thermal remote sensing in land surface processes. Boca Raton, FL: CRC, pp 33-109 + 14 colour plates

[205] Snyder W, Wan Z, Zhang Y, Feng YZ (1998) Classification-based emissivity for land surface temperature measurement from space. Int. J. Remote Sens. 19:2753-2774

[206] Payan V, Royer A (2004) Spectral emissivity of northern land cover types derived with MODIS and ASTER sensors in MWIR and LWIR. Research Note, Can. J. Remote Sens. 30(2):150-156

[207] Peres L, DaCamara C (2005) Emissivity maps to retrieve land-surface temperature from MSG/SEVIRI. IEEE Trans. Geosci. Remote Sens. 43(8):18341844

[208] Gillespie A (1985) Lithologic mapping of silicate rocks using TIMS. In: The TIMS data user workshop, June 18-19, 1985. Vol 86-38, JPL Publication, pp 29-44

[209] Mushkin A, Balick LK, Gillespie AR (2005) Extending surface temperature and emissivity retrieval to the mid-infrared (3-5 $\mu \mathrm{m})$ using the Multispectral Thermal Imager (MTI). Remote Sens. Environ. 98 141-151

[210] Gillespie A, Rokugawa S, Matsunaga T, Cothern S, Hook S, Kahle A (1998) A temperature and emissivity separation algorithm for Advanced Spaceborne Thermal Emission and Reflection radiometer (ASTER) images. IEEE Trans. Geosci. Remote Sens. 36:1113-1126

[211] Liang S (2001) An optimization algorithm for separating land surface temperature and emissivity from multispectral thermal infrared imagery. IEEE Trans. Geosci. Remote Sens. 39:264-274

[212] Mushkin A, Balick LK, Gillespie AR (2002) Temperature/emissivity separation of MTI data using the Terra/ASTER TES algorithm. In: Shen SS, Lewis PE (eds) (2002) Proceedings of SPIE - Algorithms and Technologies for Multispectral, Hyperspectral, and Ultraspectral Imagery VIII. Vol 4725, pp 328-337

[213] Gu D, Gillespie AR (2000) A new approach for temperature and emissivity separation. Int. J. Remote Sens. 212127-2132

[214] Ogawa K, Schmugge T, Jacob F, French A (2002) Estimation of broadband land surface emissivity from multispectral thermal infrared remote sensing. Agronomie: Agric. Environ. 22:695-696

[215] Peres L, DaCamara C (2004) Inverse problems theory and application: analysis of the two-temperature method for land-surface temperature and emissivity estimation. Geosci. Remote Sens. Lett. 1(3):206-210

[216] Wan Z, Li ZL (1997) A physics-based algorithm for retrieving land-surface emissivity and temperature from EOS/MODIS data. IEEE Trans. Geosci. Remote Sens. 35:980-996

AQ: Please check the page range. 
[217] Watson K (1992) Two-temperature method for measuring emissivity. Remote Sens. Environ. 42:117-121

[218] Boyd D, Petitcolin F (2004) Remote sensing of the terrestrial environment using middle infrared radiation (3.0-5.0 $\mu \mathrm{m})$. Int. J. Remote Sens. 25(17):3343-3368

[219] Huntingford C, Verhoef A, Stewart J (2000) Dual versus single source models for estimating surface temperature of African Savannah. Hydrol. Earth Sci. Syst. 4(1):185-191

[220] Kustas W, Choudhury B, Moran M, Reginato R, Jackson R, Gay L, Weaver H (1989) Determination of sensible heat flux over sparse canopy using thermal infrared data. Agric. Forest Meteorol. 44:197-216

[221] Moran M, Kustas W, Vidal A, Stannard D, Blanford J, Nichols W (1994) Use of ground-based remotely sensed data for surface energy balance evaluation of a semiarid rangeland. Water Res. Res. 30:1339-1349

[222] Stewart J, Kustas W, Humes K, Nichols W, Moran M, de Bruin H (1994) Sensible heat flux - radiometric surface temperature relationship for eight semiarid areas. J. Appl. Meteorol. 33:1110-1117

[223] Sun J, Mahrt L (1995) Determination of surface fluxes from the surface radiative temperature. J. Atmos. Sci. 52(8):1096-1106

[224] Cahill A, Parlange M (1997) On the Brutsaert temperature roughness length model for sensible heat flux estimation. Water Res. Res. 10:2315-2324

[225] Lhomme J, Troufleau D, Monteny B, Chehbouni A, Bauduin S (1997) Sensible heat flux and radiometric surface temperature over sparse Sahelian vegetation II. A model for the $\mathrm{kB}^{-1}$ parameter. J. Hydrol. 188-189:839-854

[226] Verhoef A, De Bruin H, Van Den Hurk B (1997) Some practical notes on the $\mathrm{kB}^{-1}$. J. Appl. Meteorol. 36:560-572

[227] Qualls R, Yates D (2001) Directional radiometric temperature profiles within a grass canopy. Adv. Water Res. 24:145-155

[228] Molder M, Lindroth A (2001) Dependence of $\mathrm{kB}^{-1}$ factor on roughness Reynolds number for barley and pasture. Agric. Forest Meteorol. 106: 147-152

[229] Molder M, Kellner E (2002) Excess resistance of bog surfaces in central Sweden. Agric. Forest Meteorol. 112:23-30

[230] Prévot L, Brunet Y, Paw UK, Seguin B (1993) Canopy modeling for estimating sensible heat flux from thermal infrared measurements. In: Workshop on Thermal Remote Sensing of the Energy Balance Over Vegetation in Conjunction with Other Sensor, La Londe les Maures, 20-23 September. Vol 93, pp $17-30$

[231] Norman J, Kustas W, Humes K (1995) Source approach for estimating soil and vegetation energy fluxes in observations of directional radiometric surface temperature. Agric. Forest Meteorol. 77:263-293

[232] Kustas W, Norman J (1999) Evaluation of soil and vegetation heat flux predictions using a simple two-source model with radiometric temperatures for partial canopy cover. Agric. Forest Meteorol. 94:13-29 
[233] Kustas W, Norman J (2000) A two source energy balance approach using directional radio-metric temperature observations for sparse canopy covered surfaces. Agron. J. 92:847-854

[234] Olioso A (1995) Estimating the difference between brightness and surface temperatures for a vegetal canopy. Agric. Forest Meteorol. 72:237-242

[235] Lagouarde JP, Kerr Y, Brunet Y (1995) An experiment study of angular effects on surface temperature for various plant canopies and bare soils. Agric. Forest Meteorol. 77:167-190

[236] Verbrugghe M, Cierniewski J (1998) Influence and modeling of view angles and micro-relief on surface temperature measurements of bare agricultural soils. ISPRS J. Photogramm. Remote Sens. 53:166-173

[237] Sobrino J, Cuenca J (1999) Angular variation of thermal infrared emissivity for some natural surfaces from experimental measurements. Appl. Opt. 38(18):3931-3936

[238] Weiss M, Baret F, Leroy M, Hautecoeur O, Bacour C, Prévot L, Bruguier N (2002) Evaluation of Neural Network techniques to estimate canopy biophysical variables from remote sensing data. Agronomie: Agric. Environ. 22547553

[239] Bastiaanssen W, Menenti M, Feddes R, Holtslag A (1998) A remote sensing surface energy balance algorithm for land (SEBAL). I: formulation. J. Hydrol. 212-213:198-212

[240] Su Z, Yacob A, Wen J, Roerink G, He Y, Gao B, Boogaard H, van Diepen C (2003) Assessing soil moisture with remote sensing data: theory, experimental validation, and application to drought monitoring over the North China Plain. Phys. Chem. Earth 28:89-101

[241] Brisson N, Gary C, Justes E, Roche R, Mary B, Ripoche D, Zimmer D, Sierra J, Bertuzzi P, Burger P, Bussière F, Cabidoche Y, Cellier P, Debaeke P, Gaudillère J, Hénault C, Maraux F, Seguin B, Sinoquet H (2003) An overview of the crop model STICS. Eur. J. Agron. 18:309-332

[242] Mougin E, Lo Seen D, Rambal S, Gaston A, Hiernaux P (2004) A regional sahelian grassland model to be coupled with multispectral satellite data. I: model description and validation. Remote Sens. Environ. 52:181-193

[243] Pellenq J, Boulet G (2004) A methodology to test the pertinence of remotesensing data assimilation into vegetation models for water and energy exchange at the land surface. Agronomie 24:197-204

[244] Lauvernet C, Baret F, Le Dimet FX (2003) Assimilating high temporal frequency SPOT data to describe canopy functioning: the ADAM project. In: Geoscience and Remote Sensing Symposium, 2003. IGARSS '03. Proceedings. 2003 IEEE International. Vol 5, pp 3184-3186

[245] Delécolle R, Maas S, Guérif M, Baret F (1992) Remote sensing and crop production model: present trends. ISPRS J. of Photogramm. Remote Sens. 47:145-161

[246] Weiss M, Troufleau D, Baret F, Chauki H, Prévot L, Olioso A, Bruguier N, Brisson N (2001) Coupling canopy functioning and radiative transfer models for remote sensing data assimilation. Agric. Forest Meteorol. 108:113-128 
[247] Moulin S, Kergoat L, Cayrol P, Dedieu G, Prévot L (2002) Calibration of a coupled canopy functioning and SVAT model in the ReSeDA experiment. Towards the assimilation of SPOT/HRV observations into the model. Agronomie: Agric. Environ. 22:681-686

[248] Prévot L, Chauki H, Troufleau D, Weiss M, Baret F, Brisson N (2003) Assimilating optical and radar data into the STICS crop model for wheat. Agronomie: Agric. Environ. 23:297-303

[249] Ottlé C, Vidal-Madjar D (1994) Assimilation of soil moisture inferred from infrared remote sensing in a hydrological model over the HAPEXMOBILHY region. J. Hydrol. 158:241-264

[250] van den Hurk B, Bastiaanssen W, Pelgrum H. van Meijgaard E (1997) A new methodology for assimilation of initial soil moisture fields in weather prediction models using ME-TEOSAT and NOAA data. J. Appl. Meteorol. $36: 1271-1283$

[251] Chehbouni A, Njoku E, Lhomme JP, Kerr Y (1995) Approaches for averaging surface parameters and fluxes over heterogeneous terrain. J. Climate 8:13861393

[252] Njoku E, Hook S, Chehbouni A (1996) Effects of surface heterogeneity on thermal remote sensing of land parameters, Chapter 2. In: Scaling up in hydrology using remote sensing. John, West Sussex, pp 19-31

[253] Su Z, Pelgrum H, Menenti M (1999) Aggregation effects of surface heterogeneity in land surface processes. In: Su Z, Menenti M (eds), Hydrology and Earth Science System. Vol 3, pp 549-563

[254] Bouguerzaz FA, Olioso A, Raffy M (1999) Modeling radiative and energy balance on heterogeneous areas from measured radiances. Can. J. Remote Sens. 25(4):412-424

[255] Kustas W, Norman J (2000) Evaluating the effects of subpixel heterogeneity on pixel average fluxes. Remote Sens. Environ. 74:327-342

[256] Chehbouni A, Watts C, Kerr Y, Dedieu G, Rodriguez JC, Santiago F, Cayrol P, Boulet G, Goodrich D (2000) Methods to aggregate turbulent fluxes over heterogeneous surfaces: application to SALSA data set in Mexico. Agric. Forest Meteorol. 105133-144

[257] French A, Schmugge T, Kustas W, Brubaker K, Prueger J (2003) Surface energy fluxes over El Reno, Oklahoma using high resolution remotely sensed data. Water Res. Res. 39:1164

[258] Brunsell N, Gillies R (2003) Scale issues in land atmosphere interactions: implications for remote sensing of the surface energy balance. Agric. Forest Meteorol. 117:203-221

[259] Kustas W, Li F, Jackson T, Prueger J, MacPherson J, Wolde M (2004) Effects of remote sensing pixel resolution on modeled energy flux variability of croplands in Iowa. Remote Sens. Environ. 92:535-547

[260] Lyons T, Halldin S (2004) Surface heterogeneity and the spatial variation of fluxes. Agric. Forest Meteorol. 121:153-165 
[261] Norman J, Anderson M, Kustas W, French A, Mecikalski J, Torn R, Diak G, Schmugge T, Tanner B (2003) Remote sensing of surface energy fluxes at $10^{-1} \mathrm{~m}$ pixel resolutions. Water Res. Res. 39:1221

[262] Cardot H, Faivre R, Goulard M (2003) Functional approaches for predicting land use with the temporal evolution of coarse resolution remote sensing data. J. Appl. Stat. 30(10):1185-1199

[263] Anderson M, Norman J, Diak G, Kustas W, Mecikalski J (1997) A two-source time integrated model for estimating surface fluxes using thermal infrared remote sensing. Remote Sens. Environ. 60:195-216

[264] Guillevic P (1999) Modélisation des bilans radiatif et énergétique des couverts végétaux. Ph.D. thesis, Université Paul Sabatier - Toulouse III, 181pp.

[265] Schmugge T, Ogawa K (2006) Validation of Emissivity Estimates from ASTER and MODIS Data. In: Geoscience and Remote Sensing Symposium, 2006. IGARSS '06. Proceedings. 2006 IEEE International. Vol I, pp 260-262 


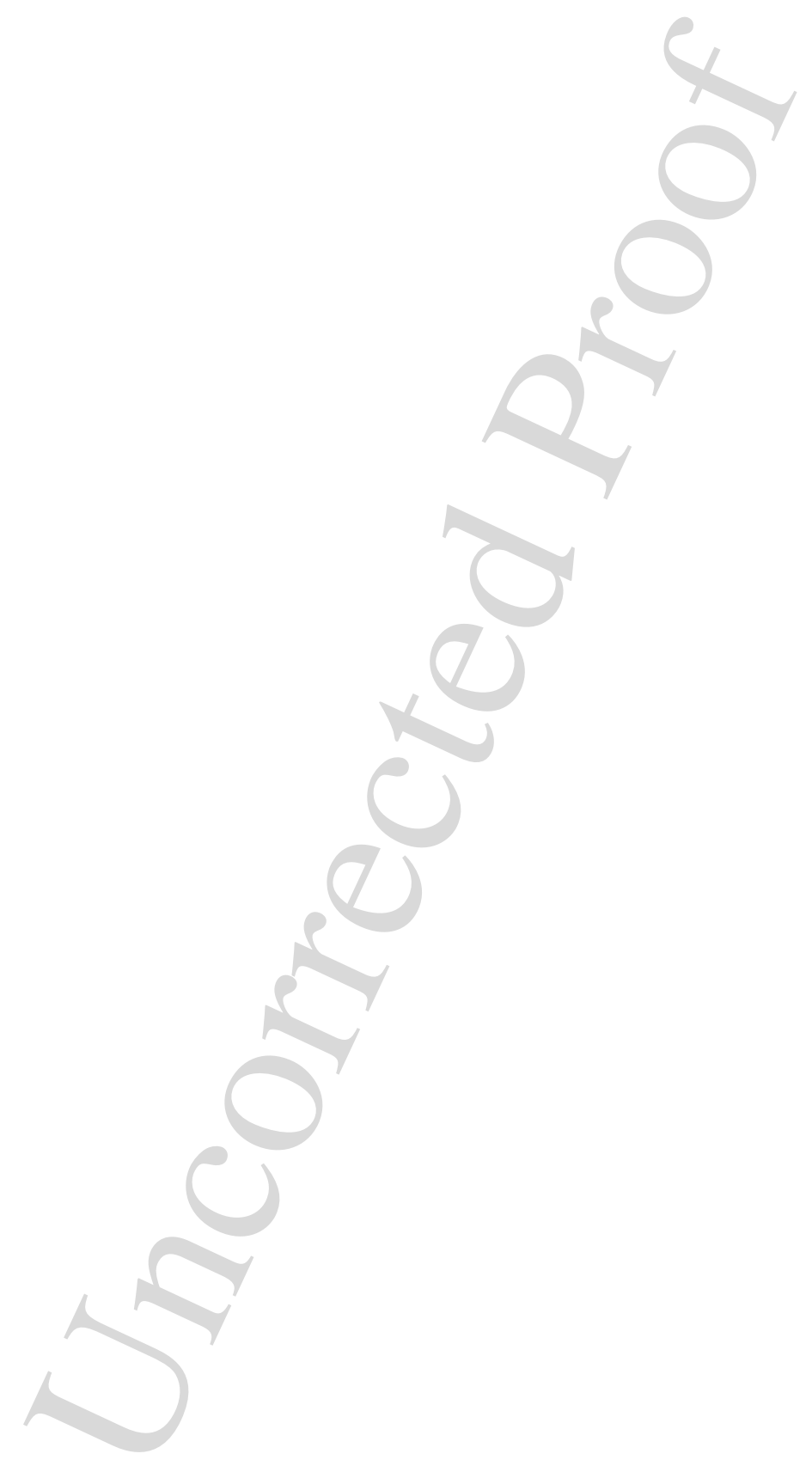




\section{Glossary}

AATSR Advanced ATSR

ANEM Adjusted NEM

ASTER Advanced Spaceborne Thermal Emission and Reflection Radiometer ATSR Along-Track Scanning Radiometer

AVHRR Advanced Very High Resolution Radiometer

DA Dual Angle differencing method

DAIS Digital Airborne Imaging Spectrometer

DAISEX DAIS EXperiment

DART Discrete Anisotropic Radiative Transfer

DART-EB DART-Energy Balance

EFEDA European Field Experiment in Desertification threatened Areas

ENVISAT ENVIronment SATellite

ERS European Remote Sensing

ETM Enhanced Thematic Mapper

FIFE First ISLSCP Field Experiment

FLUXNET Flux Network

FTIR Fourier Transform Infra Red spectroradiometer

GLI GLobal Imager

HAPEX Hydrology Atmosphere Pilot EXperiment

HIRS High-resolution Infrared Radiation Sounder

IASI Infrared Atmospheric Sounding Interferometer

IRSUTE Infra Red Satellite Unit for the Thermal Environment

ISLSCP International Satellite Land Surface Climatology Project

JORNEX JORNada EXperiment
AQ: Please check for the placement of Glossary. 
LAI Leaf Area Index

LIDF Leaf Inclination Distribution Function

MAS MODIS Airborne Simulator

MASTER MODIS / ASTER airborne simulator

METOP METeorological OPerational

MIR Middle Infra Red: from 3 to $5 \mu \mathrm{m}$

MODIS MODerate resolution Imaging Spectroradiometer

MSG Meteosat Second Generation

MTI Multispectral Thermal Imager

NDVI Normalized Difference Vegetation Index

NEM Normalized Emissivity Method

NOAA National Oceanic and Atmospheric Administration

NPOESS National Polar Orbiting Environmental Sensor Suite

NTB Narrowband To Broadband conversion

ReSeDA REmote SEnsing Data Assimilation (European research program)

SAIL Scattering by Arbitrarily Inclined Leaves

SALSA Semi Arid Land Surface Atmosphere (Mexico-United States-France joint research program)

SEBASS Spatially Enhanced Broadband Array Spectrograph System

SEVIRI Spinning Enhanced Visible and Infrared Imager

SMACEX Soil Moisture Atmosphere Coupling Experiment

SPECTRA Surface Processes and Ecosystem Changes Through Response

Analysis (proposal for a European Space Agency mission)

SVAT Soil-Vegetation-Atmosphere Transfer

SW Split Window differencing method

SWVCR Split Window Variance Covariance Ratio

TES Temperature Emissivity Separation

TIMS Thermal Infrared Multispectral Scanner

TIR Thermal Infra Red: from 7 to $14 \mu \mathrm{m}$

TIROS Television Infra Red Observation Satellite

TISIE Temperature Independent Spectral Indices of Emissivity

TM Thematic Mapper

TOVS TIROS Operational Vertical Sounders

TTM Two Temperature Method

VIIRS Visible Infrared Imaging Radiometer Suite 